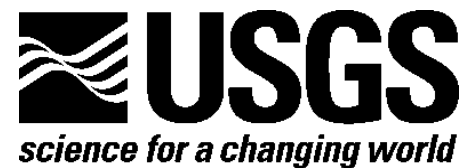

The work described in this report was performed in cooperation with the U.S. Department of Energy and the U.S. Department of the Interior Bureau of Ocean Energy Management

\title{
Processing of Multichannel Seismic Reflection Data Acquired in 2013 for Seismic Investigations of Gas Hydrates in the Gulf of Mexico
}

By John J. Miller, Warren F. Agena, Seth S. Haines, and Patrick E. Hart

Open-File Report 2016-1037

U.S. Department of the Interior

U.S. Geological Survey 


\section{U.S. Department of the Interior \\ SALLY JEWELL, Secretary}

\section{U.S. Geological Survey \\ Suzette M. Kimball, Director}

U.S. Geological Survey, Reston, Virginia: 2016

For more information on the USGS-the Federal source for science about the Earth,

its natural and living resources, natural hazards, and the environment-visit

http://www.usgs.gov/ or call 1-888-ASK-USGS (1-888-275-8747).

For an overview of USGS information products, including maps, imagery, and publications, visit http://www.usgs.gov/pubprod/.

Any use of trade, firm, or product names is for descriptive purposes only and does not imply endorsement by the U.S. Government.

Although this information product, for the most part, is in the public domain, it also may contain copyrighted materials as noted in the text. Permission to reproduce copyrighted items must be secured from the copyright owner.

Suggested citation:

Miller, J.J., Agena, W.F., Haines, S.S., and Hart, P.E., 2016, Processing of multichannel seismic reflection data acquired in 2013 for seismic investigations of gas hydrates in the Gulf of Mexico: U.S. Geological Survey Open-File Report 2016-1037, 32 p., http://dx.doi.org/10.3133/ofr20161037.

ISSN 2331-1258 (online) 


\section{Contents}

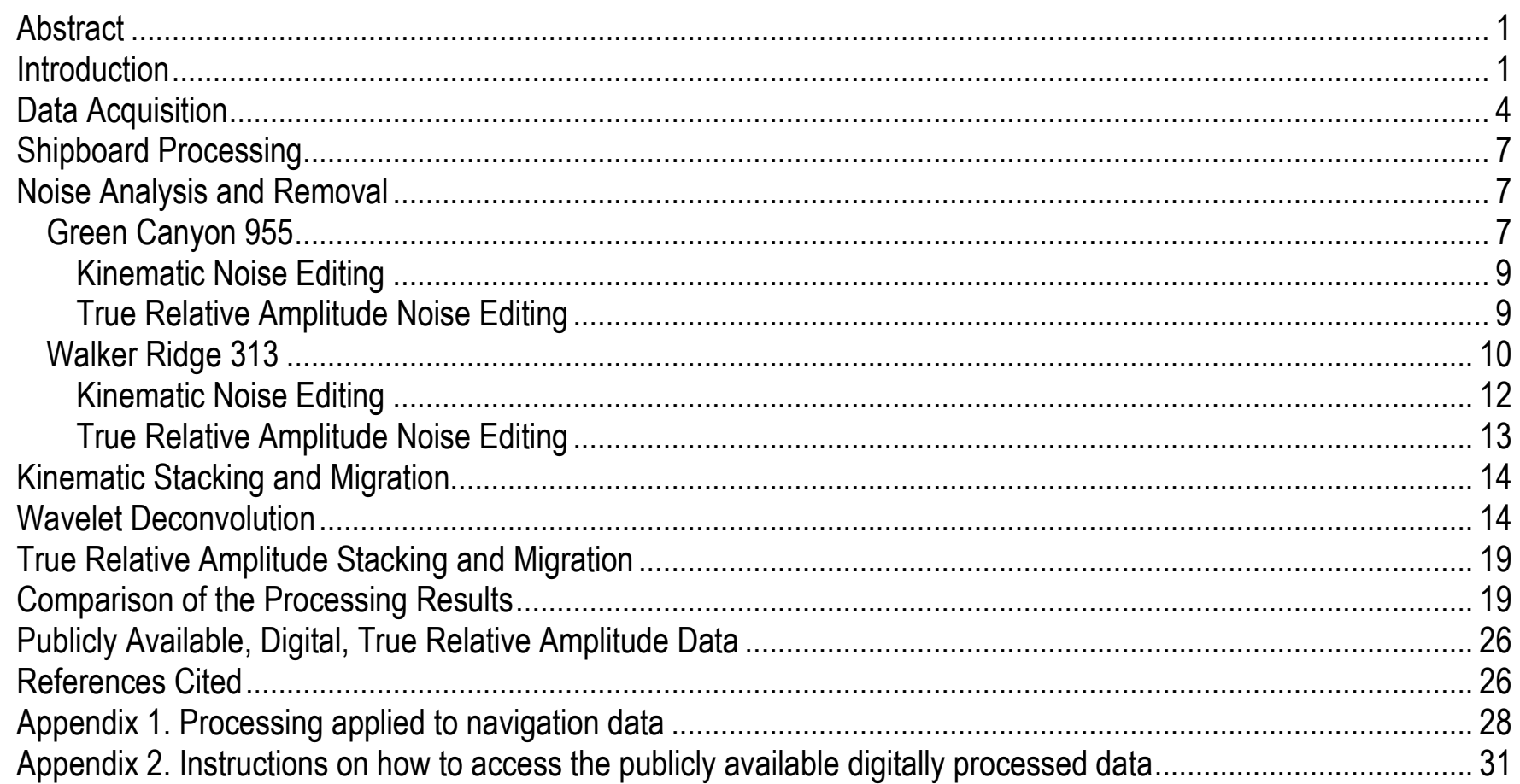




\section{Figures}

1. Map showing Gulf of Mexico bathymetry; Cocodrie, Louisiana; and Green Canyon 955 and Walker Ridge 313 study sites

2. Map showing 2013 seismic transects and ocean-bottom seismometer deployments at

Green Canyon 955

3. Map showing 2013 seismic transects and ocean-bottom seismometer deployments at

Walker Ridge 313.

4. Example of noise on shot records from Green Canyon 955 line and shot records

after application of time-frequency-domain noise removal.

5. Shot records shown in figure 4 after applying the U.S. Geological Survey-developed automatic noise editing and noise burst removal.

6. Example of linear noise on shot records from Walker Ridge 313 line, shot records after the application of the frequency-wavenumber filter, and manual edit of shot records from top

7. Noise as manifested in the common-offset domain, and result after time-frequency-domain processing.

8. Wavelet extraction, calculation of inverse filter, and conversion to zero-phase wavelet......

9. Walker Ridge unmigrated stack with no deconvolution applied and data from top with prestack wavelet deconvolution applied

10. Unmigrated stack from Green Canyon with no deconvolution applied and data from top with wavelet deconvolution applied....

11. Comparison of shipboard processing with basic processing performed in Denver, Colorado

12. Comparison of kinematic, true relative amplitude, and migration of true relative amplitude processing ...... 21

13. Area within green boxes on figures 11 and 12 with scaling only, no deconvolution, section processed after manual and automatic removal of noise and true relative amplitude scaling, and noise editing, wavelet deconvolution, and true relative amplitude scaling.

14. Area contained within green boxes on figure 12 with unmigrated stack with wavelet deconvolution and true relative amplitude processing and migrated data from top

15. Area contained within red boxes on figure 12 with unmigrated and migrated true relative amplitude-processed sections

1-1. Maps of common mid-point positions for line Green Canyon 151

1-2. Maps of common mid-point positions for line Green Canyon 103 


\section{Conversion Factors}

Inch/Pound to SI

\begin{tabular}{lll}
\hline \multicolumn{1}{c}{ Multiply } & \multicolumn{1}{c}{ By } & \multicolumn{1}{c}{ To obtain } \\
\hline foot $(\mathrm{ft})$ & 0.3048 & meter $(\mathrm{m})$ \\
mile $(\mathrm{mi})$ & 1.609 & kilometer $(\mathrm{km})$ \\
mile, nautical $(\mathrm{nmi})$ & 1.852 & kilometer $(\mathrm{km})$ \\
\hline & Volume & \\
\hline cubic inch $\left(\mathrm{in}^{3}\right)$ & 0.01639 & liter $(\mathrm{L})$ \\
cubic foot $\left(\mathrm{ft}^{3}\right)$ & 0.02832 & cubic meter $\left(\mathrm{m}^{3}\right)$ \\
\hline & Flow rate & \\
\hline foot per second $(\mathrm{ft} / \mathrm{s})$ & 0.3048 & meter per second $(\mathrm{m} / \mathrm{s})$ \\
\hline & Density & \\
\hline pound per cubic foot $\left(\mathrm{lb} / \mathrm{ft}^{3}\right)$ & 0.01602 & gram per cubic centimeter $\left(\mathrm{g} / \mathrm{cm}^{3}\right)$ \\
\hline
\end{tabular}

SI to Inch/Pound

\begin{tabular}{lll}
\hline \multicolumn{1}{c}{ Multiply } & \multicolumn{1}{c}{ By } & \multicolumn{1}{c}{ To obtain } \\
\hline meter $(\mathrm{m})$ & 3.281 & foot $(\mathrm{ft})$ \\
kilometer $(\mathrm{km})$ & 0.6214 & mile $(\mathrm{mi})$ \\
kilometer $(\mathrm{km})$ & 0.5400 & mile, nautical $(\mathrm{nmi})$ \\
\hline \multicolumn{2}{c}{ Volume } \\
\hline liter $(\mathrm{L})$ & 61.02 & cubic inch $\left(\mathrm{in}^{3}\right)$ \\
cubic meter $\left(\mathrm{m}^{3}\right)$ & 35.31 & cubic foot $\left(\mathrm{ft}^{3}\right)$ \\
\hline & \multicolumn{2}{c}{ Flow rate } \\
\hline meter per second $(\mathrm{m} / \mathrm{s})$ & 3.281 & foot per second $(\mathrm{ft} / \mathrm{s})$ \\
\hline & \multicolumn{2}{c}{ Density } \\
\hline gram per cubic centimeter $\left(\mathrm{g} / \mathrm{cm}^{3}\right)$ & 62.4220 & pound per cubic foot $\left(\mathrm{lb} / \mathrm{ft}^{3}\right)$ \\
\hline
\end{tabular}

Temperature in degrees Celsius $\left({ }^{\circ} \mathrm{C}\right)$ may be converted to degrees Fahrenheit $\left({ }^{\circ} \mathrm{F}\right)$ as follows:

${ }^{\circ} \mathrm{F}=\left(1.8 \mathrm{x}^{\circ} \mathrm{C}\right)+32$

Temperature in degrees Fahrenheit $\left({ }^{\circ} \mathrm{F}\right)$ may be converted to degrees Celsius $\left({ }^{\circ} \mathrm{C}\right)$ as follows:

${ }^{\circ} \mathrm{C}=\left({ }^{\circ} \mathrm{F}-32\right) / 1.8$ 


\section{Abbreviations}

$\begin{array}{ll}\text { AGC } & \text { automatic gain control } \\ \text { BSR } & \text { bottom-simulating reflector } \\ \text { CMP } & \text { common mid-point } \\ \text { DOE } & \text { Department of Energy } \\ \text { F-K } & \text { frequency-wavenumber } \\ \text { GPS } & \text { global positioning system } \\ \text { JIP } & \text { Joint Industry Project } \\ \text { LWD } & \text { logging-while-drilling } \\ \text { m } & \text { meter } \\ \text { TFD } & \text { time-frequency-domain } \\ \text { TRA } & \text { true relative amplitude } \\ \text { TWTT } & \text { two-way travel time }\end{array}$




\title{
Processing of Multichannel Seismic Reflection Data Acquired in 2013 for Seismic Investigations of Gas Hydrates in the Gulf of Mexico
}

\author{
By John J. Miller, Warren F. Agena, Seth S. Haines, and Patrick E. Hart
}

\begin{abstract}
As part of a cooperative effort among the U.S. Geological Survey (USGS), the U.S. Department of Energy, and the U.S. Department of the Interior Bureau of Ocean Energy Management, two grids of two-dimensional multichannel seismic reflection data were acquired in the Gulf of Mexico over lease blocks Green Canyon 955 and Walker Ridge 313 between April 18 and May 3, 2013. The purpose of the data acquisition was to fill knowledge gaps in an ongoing study of known gas hydrate accumulations in the area. These data were initially processed onboard the recording ship $R / V$ Pelican for more quality control during the recording. The data were subsequently processed in detail by the U.S. Geological Survey in Denver, Colorado, in two phases. The first phase was to create a "kinematic" dataset that removed extensive noise present in the data but did not preserve relative amplitudes. The second phase was to create a true relative amplitude dataset that included noise removal and "wavelet" deconvolution that preserved the amplitude information. This report describes the processing techniques used to create both datasets.
\end{abstract}

\section{Introduction}

Gas hydrates are present in Arctic and marine settings worldwide and are of interest because of their possible role in global climate change, their potential as a substantial energy resource, and their status as a possible drilling hazard. Between 2001 and 2013, the Gulf of Mexico Gas Hydrates Joint Industry Program (JIP) brought together industry, government, and academic groups to study gas hydrate accumulations in the Gulf of Mexico using drilling, coring, logging, and three-dimensional (3D) seismic data (detailed information on the JIP is available at http://www.netl.doe.gov/technologies/oilgas/FutureSupply/MethaneHydrates/projects/DOEProjects/CharHydGOM-41330.html/). One major accomplishment of the JIP was the 2009 JIP Leg II, a logging-while-drilling (LWD) expedition in lease blocks Green Canyon 955 (GC955) and Walker Ridge 313 (WR313) (Boswell and others, 2009; Cook and others, 2009). The LWD data from GC955 indicate thick (as much as 30 meters [m]) sand layers containing gas hydrate concentrations as high as 80 percent, and the data from WR313 indicate a sequence of thinner sands with gas hydrate saturations locally as high as 90 percent (Boswell and others, 2012; Collett and others, 2012). The GC955 and WR313 JIP Leg II sites (fig. 1) host reservoir-grade gas hydrate accumulations and represent world-class gas hydrate study sites within a long-established petroleum province. The LWD data provide highly detailed characterization at the boreholes, and available industry 3D seismic data facilitate interpretations between and away from the boreholes. Away from the LWD boreholes, important questions remain regarding lithology and gas hydrate 
characterization as well as structural and stratigraphic details that cannot be resolved with the 3D seismic data. Together, the U.S. Geological Survey (USGS), U.S. Department of Energy (DOE), and U.S. Department of the Interior Bureau of Ocean Energy Management (BOEM) recognized the necessity for acquiring new geophysical data at WR313 and GC955 to fill these knowledge gaps, which led to the 2013 multichannel seismic acquisition effort (Haines and others, 2014a).

One of the newly acquired geophysical datasets recorded over each of the lease blocks was a grid of high-resolution, two-dimensional (2D) multichannel reflection seismic lines (cruise designation P1-13-LA, 2013; processed data publicly available at the National Archive of Marine Seismic Surveys (Triezenberg and others, 2016; https://walrus.wr.usgs.gov/namss/survey/p1-13-la-green-canyon/ and https://walrus.wr.usgs.gov/namss/survey/p1-13-la-walker-ridge/). These data enable substantially more detailed interpretations of the structural and stratigraphic features associated with the gas and gas hydrate systems within each lease block. Funding for the acquisition program was provided by the DOE, the BOEM, and the USGS. 


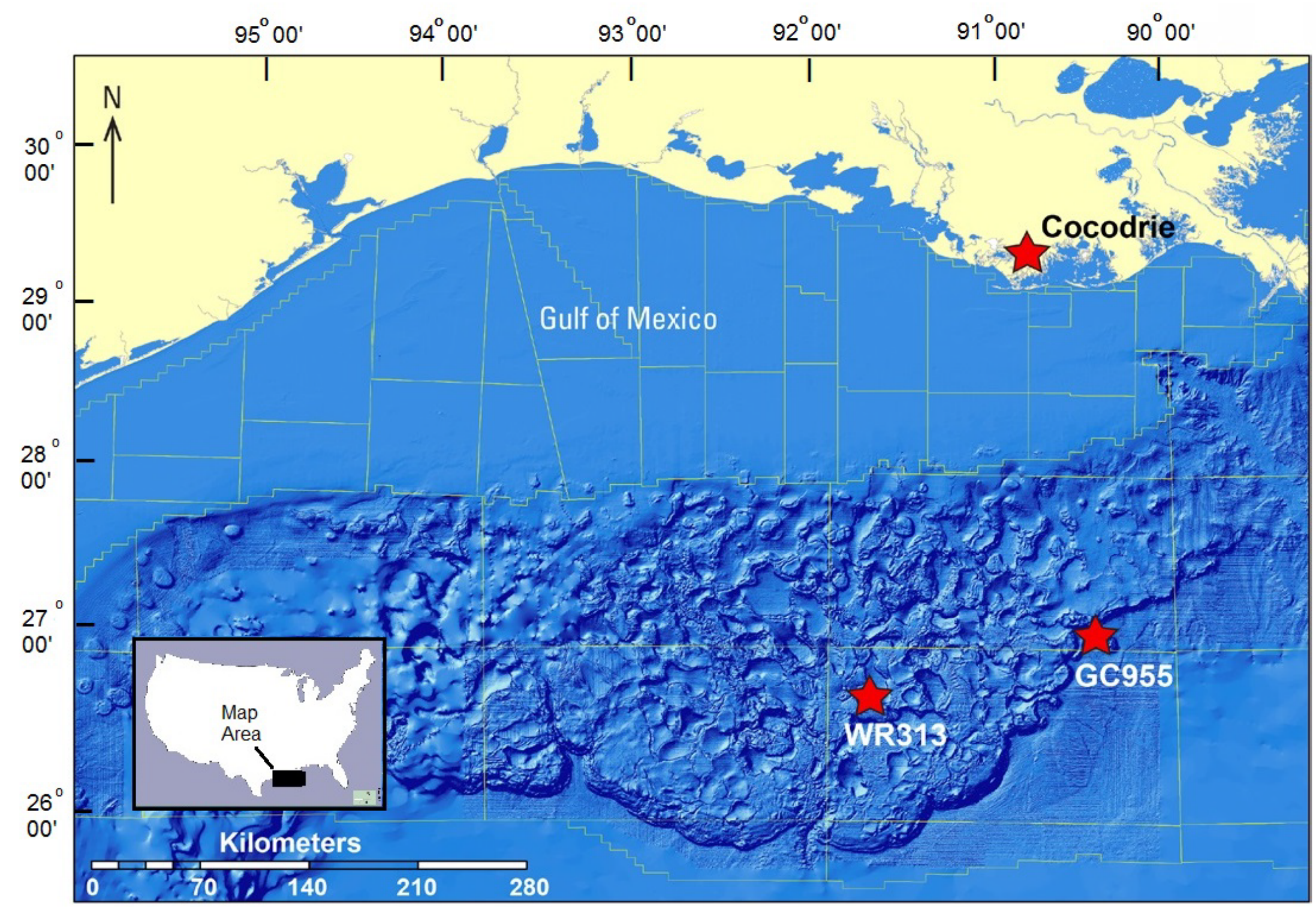

Figure 1. Map showing Gulf of Mexico bathymetry; Cocodrie, Louisiana; and Green Canyon 955 (GC955) and Walker Ridge 313 (WR313) study sites (from Haines and others, 2014a). 
During the data acquisition, the multichannel data were initially processed onboard the acquisition ship, the $R / V$ Pelican, for quality control. Although the reflections recorded were of high quality, the data still contained a high-level random and coherent noise that would have to be removed for the data to be suitable for detailed interpretation. Seismic amplitudes are related to the gas hydrate saturation and thickness of the reservoir because of constructive and destructive interferences (Miller and others, 1991; Lee, 2005). Therefore, the complex, minimum-phase source waveform would need to be collapsed into a zero-phase spike, and the noise would have to be eliminated in such a way that the relative amplitudes of the reflection events could be preserved.

We performed two complete processing flows on the data that culminated in two sets of results. First, using a conventional processing flow, we created a "kinematic" dataset that was well suited for structural interpretation but lacked relative amplitude information. Second, we created a true relative amplitude (TRA) dataset better suited to gas hydrate interpretation. The velocity models used for stacking and migration were the same for both processing flows. We performed poststack time migration of each line using a smoothed version of the stacking velocities. Processing was performed at the USGS facility in Denver, Colorado, using ProMAX2D software; version 2003.19.1 (Halliburton, Landmark Software and Solutions).

\section{Data Acquisition}

The data discussed in this report were acquired by a USGS-led seismic acquisition cruise in the Gulf of Mexico from April 18 to May 3, 2013. Two grids of intersecting 2D seismic lines were acquired at two sites, GC955 and WR313. Sixty-five lines were recorded at the GC955 site (fig. 2), and 43 lines were recorded at the WR313 site (fig. 3). In addition, data were recorded on ocean-bottom seismometers (locations shown in figs. 2 and 3), but these data were processed separately and are not addressed in this report. The acquisition operation used USGS-owned equipment to the extent possible, augmented by borrowed and leased items as necessary, and was conducted aboard the $R / V$ Pelican, a Universities National Oceanographic Laboratories System vessel owned and operated by the Louisiana Universities Marine Consortium. The seismic energy source was a pair of 105/105-cubic-inch generator/injector air guns (45/105 or 45/45 configuration for some lines), and the seismic energy was recorded using a 450 $\mathrm{m}, 72$-channel digital hydrophone streamer with minimum and maximum source-receiver offsets of 40 and $483.75 \mathrm{~m}$, respectively. The shot interval was 10 to 25 seconds (at roughly 25 to $60 \mathrm{~m}$ ) depending on the source gun configuration A detailed description of the data acquisition methodology is contained in the cruise report (Haines and others, 2014a). 


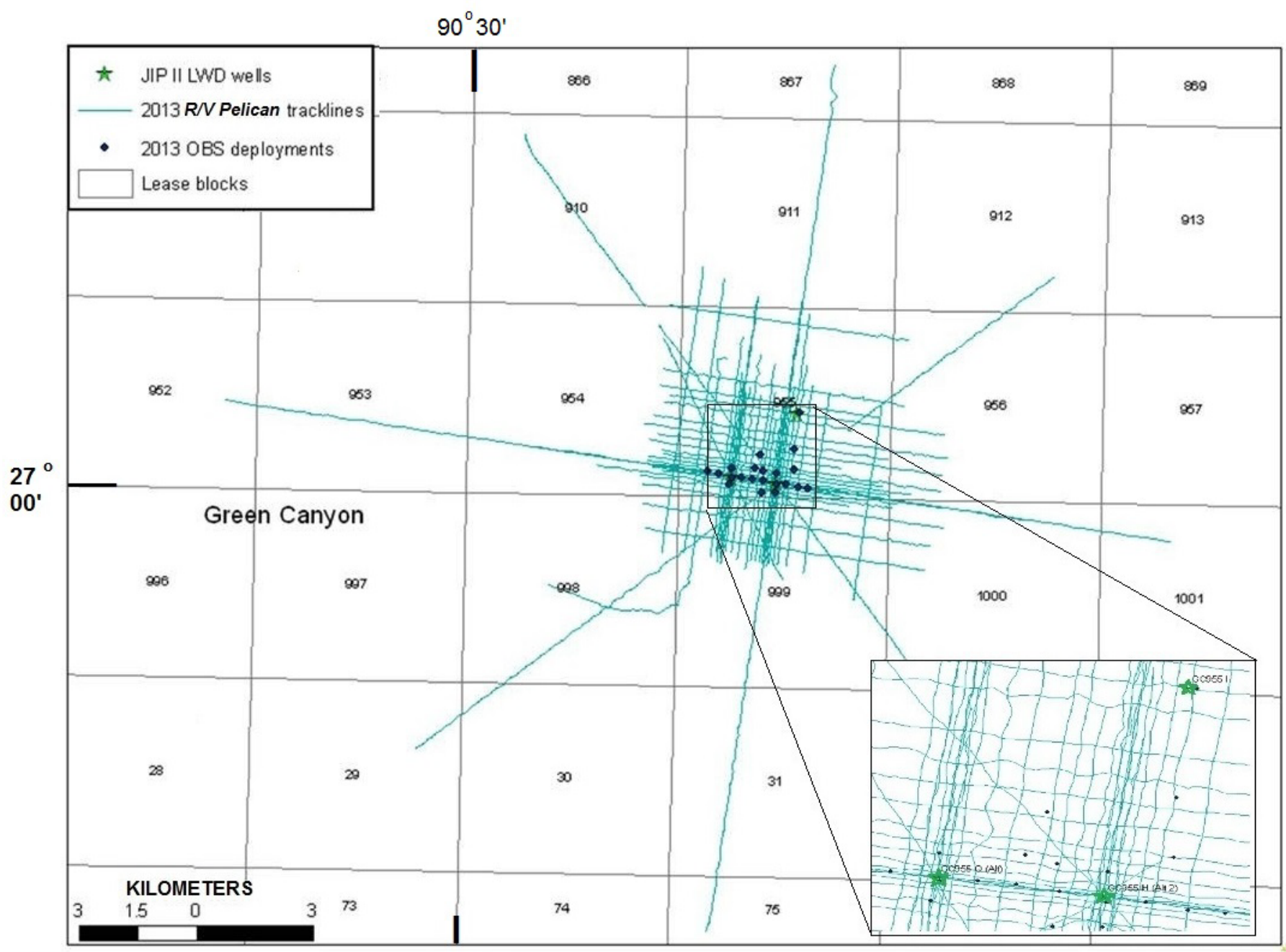

Figure 2. Map showing 2013 seismic transects and ocean-bottom seismometer deployments at Green Canyon 955 (from Haines and others, 2014a). JIP, Joint Industry Project; LWD, logging while drilling; OBS, ocean-bottom seismometer. 


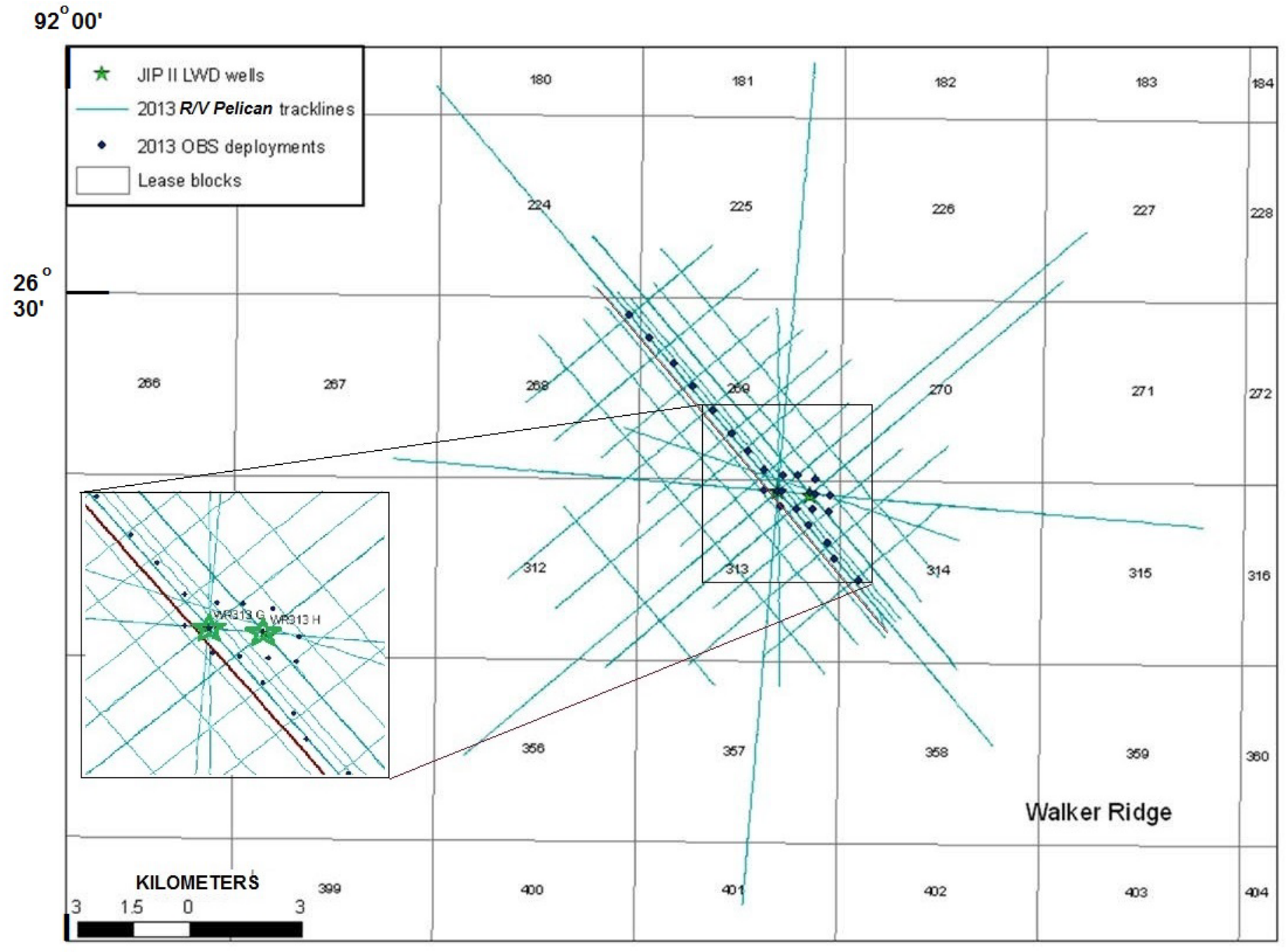

Figure 3. Map showing 2013 seismic transects and ocean-bottom seismometer deployments at Walker Ridge 313. JIP, Joint Industry Project; LWD, logging-while-drilling; OBS, ocean-bottom seismometer. 


\section{Shipboard Processing}

Raw data were processed onboard the ship using SIOSEIS public domain, open-source software sponsored by the National Science Foundation (NSF) and the Scripps Industrial Associates (http://sioseis.ucsd.edu/index.html). Data for each line were combined into a single file that included geographic coordinates for the shot and receiver locations added to the trace headers, the traces sorted from shot domain to common mid-point (CMP) domain, and SEG-Y format files of the CMP gathers output for postcruise processing. These files were also input to the SIOSEIS processing system, and each line was processed onboard through stack and poststack time migration for quality control. A detailed description of the shipboard data processing is contained in the cruise report (Haines and others, 2014a). The coordinates of the shots and receivers were stored in the trace headers of the SEG-Y files, but CMP coordinates were not stored in the trace headers.

\section{Noise Analysis and Removal}

A significant amount of noise was present in the recorded data, including noise bursts from other air gun operations near the WR313 site and wave noise caused by high seas during the first few days at GC955 (Haines and others, 2014a). Examples of both of these types of noise and our approach to removing them are described separately for both surveys and for the kinematic and TRA datasets.

\section{Green Canyon 955}

The noise on the Green Canyon lines consisted mostly of high-amplitude noise bursts on individual channels distributed randomly on each shot. A typical example of this noise is shown on figure 4 (top). From left to right, red ovals indicate (1) a high-amplitude, low-frequency channel, (2) high-amplitude, high-frequency channels, (3) anomalously low-amplitude channels, probably due to cable undulation, and (4) a high-amplitude isolated noise burst. 

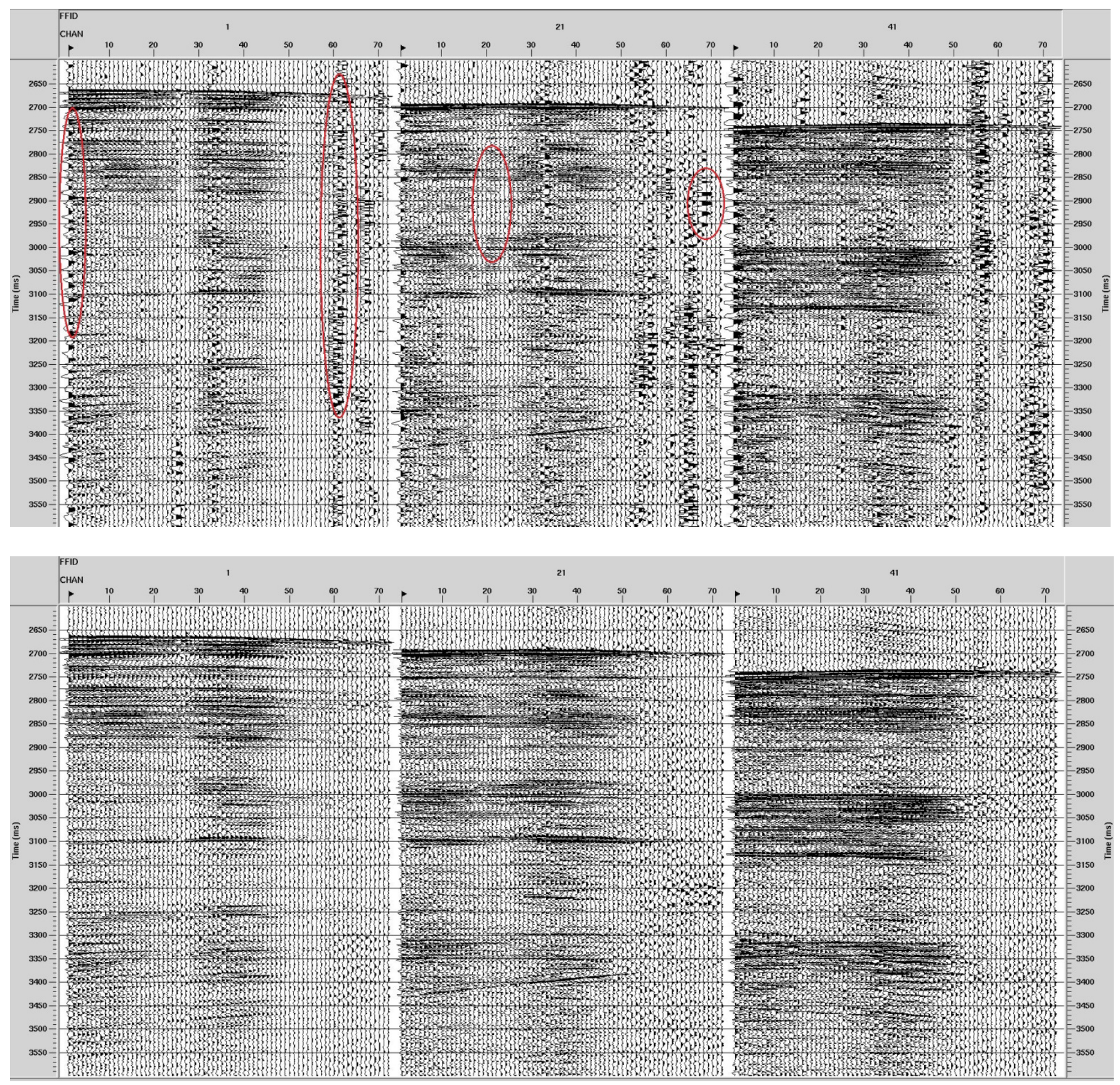

Figure 4. Top: Example of noise on shot records from Green Canyon 955 (GC955) line. Ovals indicate examples of noise. Bottom: Shot records after application of time-frequency-domain (TFD) noise removal. FFID, field file identification number; CHAN, channel: ms, millisecond. 


\section{Kinematic Noise Editing}

For the initial kinematic dataset, we used an automated noise-removal routine contained within the ProMAX2D software named time-frequency-domain noise removal (TFD). This routine tranforms each record into the time-frequency-domain using the classic short-time Fourier transform. The median spectral amplitude is calculated and multiplied by a user-supplied threshold multiplier. This number becomes the threshold value for the record. Each sample is compared to the threshold value, and, if it exceeds that value, it is replaced by the median spectral amplitude of the traces in a user-specified aperture around the trace being analyzed (usually between 5 and 7 traces). The inverse short-time Fourier transform is then applied and the data are output. Figure 4 (bottom) is an example of TFD applied to figure 4 (top). The noise has been effectively removed, but the amplitudes of the traces have been modified as well. Thus, after application of TFD, the amplitudes are no longer true in the data.

\section{True Relative Amplitude Noise Editing}

For the TRA dataset, we developed our own noise-removal technique that preserved the relative amplitudes by setting the amplitude of the noisy traces to zero. We first used an amplitude-balancing routine that calculated the average amplitude of each trace and derived a multiplication scalar that could be used to make the average amplitude of each trace equal to one. We did not, however, apply the multiplication scalar; rather, we output the scalar values. The scalars needed to balance noisy traces (those having high-amplitude bursts) were significantly smaller than those for nonnoisy traces. For example, for a particular line, a noisy trace might have an average amplitude of 200 while a nonnoisy trace might have an average amplitude of 100. The scalars required would be 0.05 and 0.01 , respectively. We would then test scalars between 0.05 and 0.01 on a subset of shots within the line; traces having scalars below each test value were blanked (amplitudes set equal to zero). The subset of shots were visually inspected to determine which scalar value eliminated the noisiest traces. That scalar value would then be used to automatically edit the entire line. There were also isolated noise bursts present that did not warrant zeroing the entire trace. Most of these were effectively removed by ProMAX2D's noise burst removal module. When the noise burst was detected, those samples were set to zero rather than averaging adjacent traces, thereby preserving the relative amplitudes. Figure 5 shows an example of shot records from figure 4 (top) with the above described editing applied. On some lines, this automatic editing was not sufficient to remove all of the noise, and thus we manually deleted that noise. The circles on figure 5 indicate noise that had to be manually deleted. 


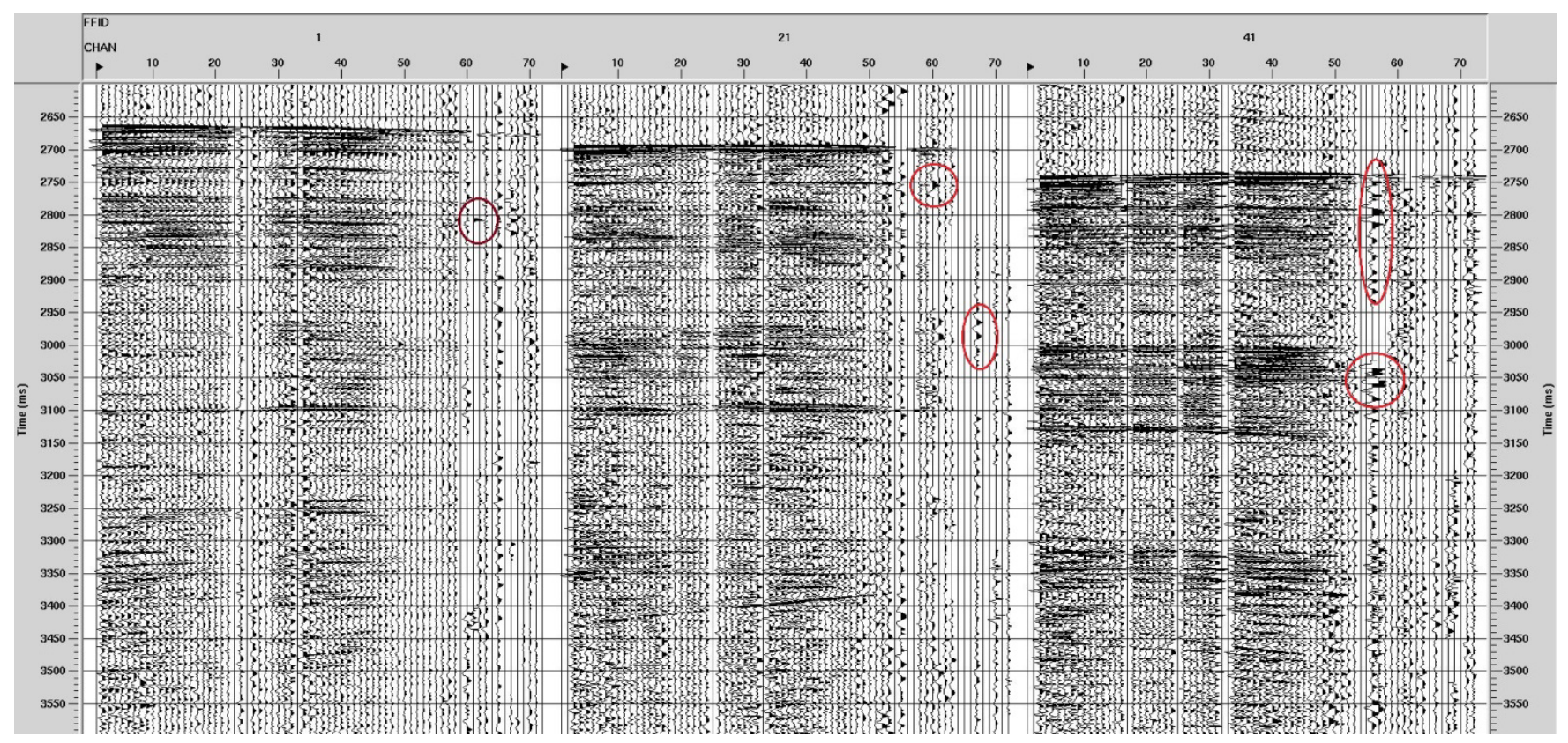

Figure 5. Shot records shown in figure 4 (top) after applying the U.S. Geological Survey-developed automatic noise editing and noise burst removal. Circles indicate noise that remained after editing and needed to be manually deleted. FFID, field file identification number; CHAN, channel: ms, millisecond.

\section{Walker Ridge 313}

The noise on the Walker Ridge lines consisted mostly of high-amplitude noise distributed linearly across the shots, caused by a nearby industry seismic survey. In addition, some short noise bursts and high-amplitude noise on individual channels were present. An example of this noise is shown in figure 6 (top). 

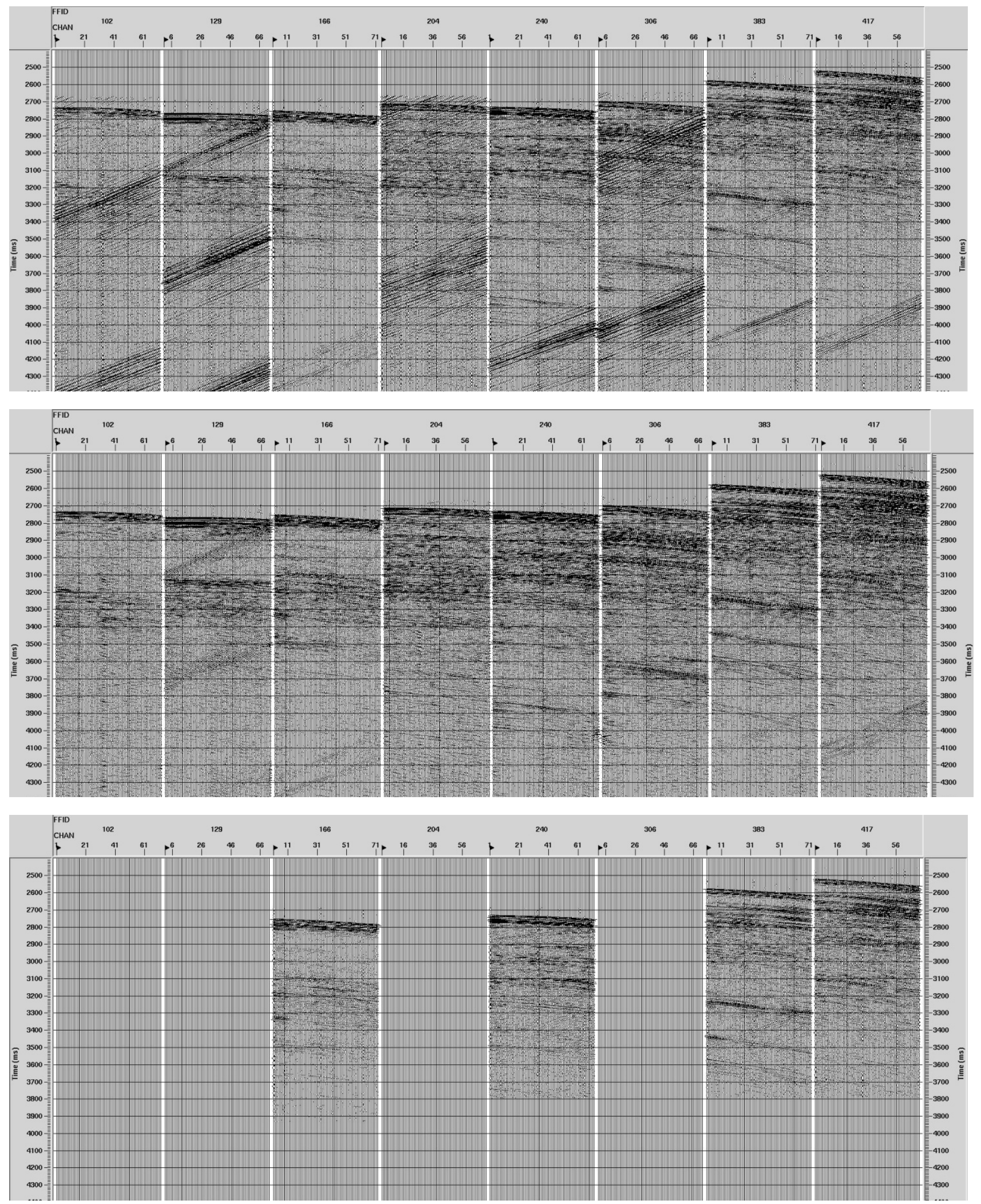

Figure 6. Top: Example of linear noise on shot records from Walker Ridge 313 (WR313) line. Middle: Shot records after the application of the frequency-wavenumber filter. The linear noise is effectively removed, but 
amplitudes have been modified. Bottom: Manual edit of shot records from top. Four records having linear noise throughout the records were completely eliminated; four records had a "bottom" mute applied, preserving usable data. Amplitudes have not been modified. This is a particularly noisy line. Most of the other lines did not require the elimination of as many records. FFID, field file identification number; CHAN, channel: ms, millisecond.

\section{Kinematic Noise Editing}

In the shot domain, the high-amplitude linear noise had, in most cases, a much steeper dip than any of the reflected energy. We used a frequency-wavenumber (F-K) filter to effectively remove this noise. Figure 6 (top) gives an example of this noise on a particularly noisy line. Figure 6 (bottom) gives an example of the linear noise after F-K filtering has been applied. Regrettably, the application of F-K filtering does not preserve the relative amplitudes of the data.

On some lines, the linear noise in the shot domain had a dip similar to that of the reflected energy and could not be removed by F-K filtering. In those cases, we used TFD processing applied in the common offset domain. In this domain, the high-amplitude noise appeared as random noise bursts across the record as shown in figure 7 (top). The TFD process effectively removed this noise, shown in figure 7 (bottom), but as with the Green Canyon TFD processing, the amplitudes of the traces have been modified and thus are no longer true in the data. 

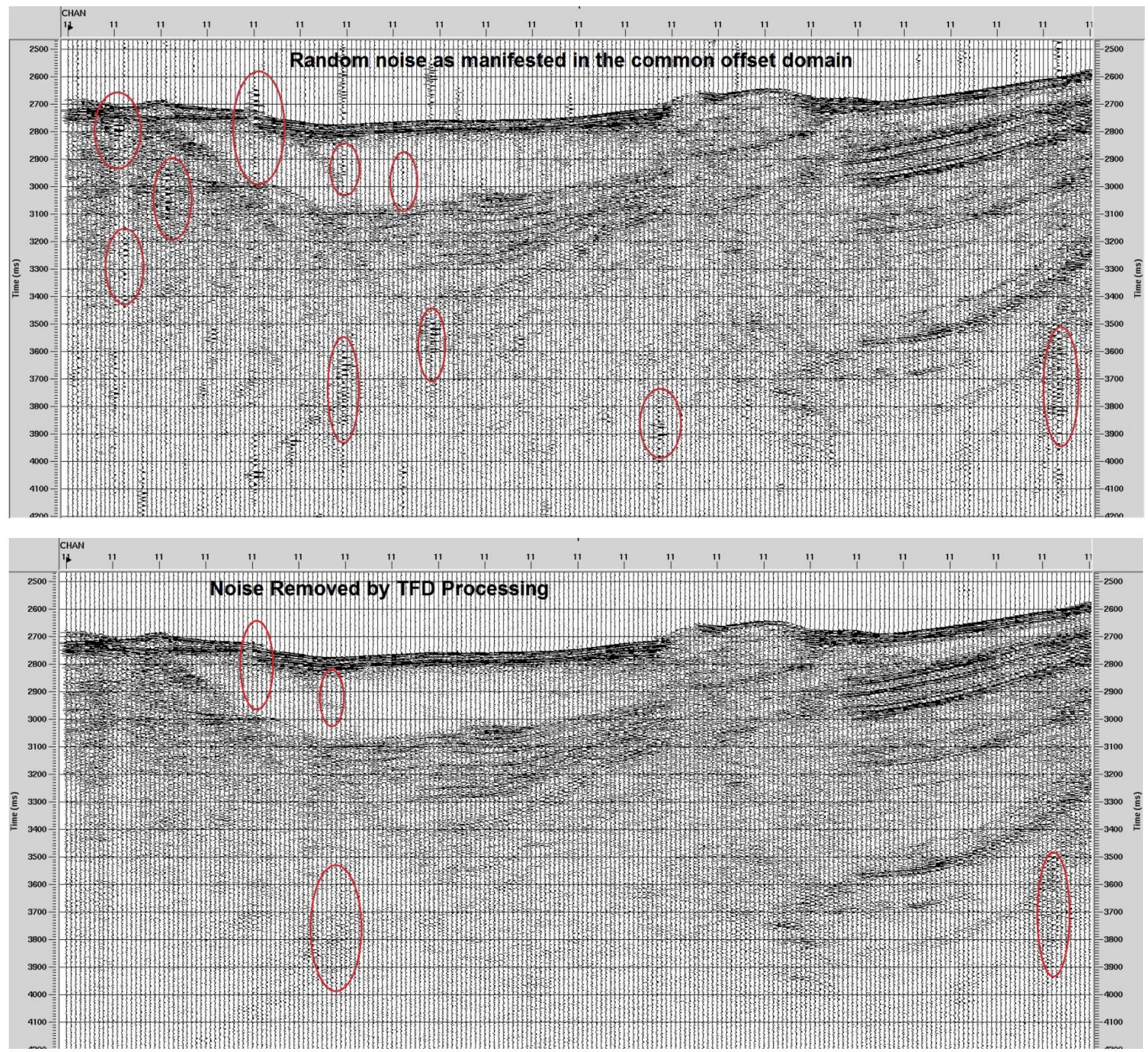

Figure 7. Top: Noise as manifested in the common-offset domain, some of which is encircled in ovals. Bottom: Result after time-frequency-domain (TFD) processing, effectively removing the noise but modifying the amplitudes. CHAN, channel; ms, millisecond.

\section{True Relative Amplitude Noise Editing}

We were unable to devise an automatic editing routine, like the method used on the Green Canyon dataset, to preserve the relative amplitudes of the Walker Ridge dataset. The high-amplitude linear noise on most lines was so severe that we were forced to either delete entire shots with such noise throughout the record or "mute" the record from the position of the noise down to the bottom of the record. Figure 6 
(bottom) gives an example of this type of editing applied to the data from figure 6 (top). In addition, ProMAX2D's noise burst removal module was used where necessary to detect any remaining noise bursts and to set those amplitudes to zero.

\section{Kinematic Stacking and Migration}

As mentioned in the previous section, the initial noise-removal techniques (F-K filtering, automatic time-frequency-domain noise removal, and ProMAX2D noise burst removal) were very successful in removing the noise but did not preserve the relative amplitudes of the data. The data with the noise removed in this manner were input to a relatively conventional processing flow as follows:

Scaling-1: Programmed gain function of two-way travel time (TWTT) raised to the power of 2 (T-squared gain) applied to 5-s maximum TWTT.

Scaling-2: Single window balance on every trace; design window=seafloor-100 millisecond (ms), to slightly above seafloor multiple.

Deconvolution: Spiking deconvolution on every trace; single window design; 80 -ms filter length; same design window as single-window balance.

Velocity analysis: Semblance and constant velocity stacks (pre-analysis bandpass filter +300 $\mathrm{ms}$ automatic gain control (AGC) applied for velocity analysis only). Velocity functions were picked at a nominal 1.5-kilometer interval plus at places where the seafloor reached a high or low point or changed dip significantly. The initial guide function was that used for the shipboard processing (Haines and others, 2014a).

Bandpass filter: $35-375 \mathrm{Hertz}(\mathrm{Hz})$ butterworth.

NMO correction and stacking: 1/square root (fold) mute compensation.

Velocity manipulation: Smooth stacking velocity model over 101 CMPs horizontally and 100 ms vertically and output the result at a $300-\mathrm{m}$ interval.

Poststack time migration: Stolt F-K algorithm using the smoothed velocity model (Stolt, 1978; Claerbout, 1985; Yilmaz, 1987; Deregowski, 1990).

Initial interpretations and analysis of selected lines from the kinematic dataset are given in Haines and others (2013).

\section{Wavelet Deconvolution}

Collapsing the complex minimum-phase source waveform into a zero-phase spike simplified interpretation and facilitated quantitative gas hydrate estimation. Although the spiking deconvolution performed during the kinematic processing approximated this goal, a problem arose in that a separate filter was calculated for each trace in the dataset, when we know that the source wavelet should be relatively consistent from shot-to-shot along each line. Therefore, in place of spiking deconvolution, we used an algorithm that derived an average wavelet for each line (Oppenheim and Schafer, 1975). The input for the wavelet derivation was every shot in the line after application of TRA noise editing. The design window length was 1 second, beginning at the seafloor. A 100-ms AGC was applied to eliminate spurious noise. Once the average wavelet was derived, we calculated an inverse filter that converted the wavelet to a zero-phase spike. That inverse filter was then applied to all of the shots in the line after noise editing but without $\boldsymbol{A} \boldsymbol{G C}$.

Figure 8 (top) shows the source wavelets derived from WR313 lines 223 through 241 . The sources were $2 \times 45 / 45$ cubic inches except where noted. For each of the different sources, the derived wavelets are quite similar. Figure 8 (middle) is an expanded version of the top figure displayed at increased gain to show the consistency in the wavelet tails for the two different sources. Figure 8 
(bottom) gives an example of an extracted wavelet, the inverse filter calculated to convert the minimumphase source wavelet to a zero-phase wavelet, and the result of the convolution of the wavelet with the filter.
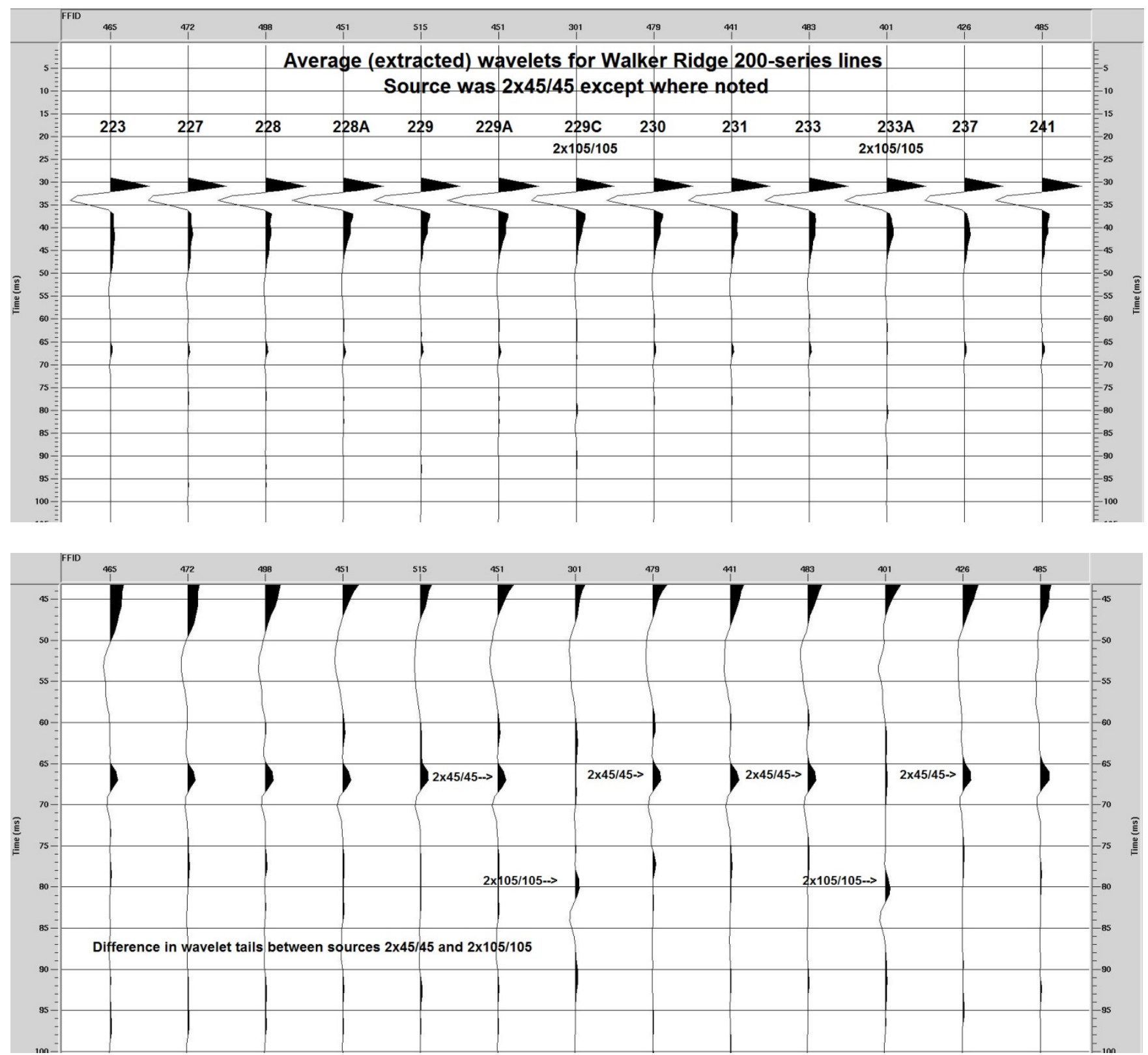

Figure 8. Wavelet extraction, calculation of inverse filter, and conversion to zero-phase wavelet. Top: Average wavelets extracted from the Walker Ridge 200-series lines. The sources were $2 \times 45 / 45$ cubic inches except where noted. For each source, the extracted wavelets are quite similar. Middle: Enlarged version of top displayed at higher gain, showing the consistency in the wavelet tails for the different sources. Bottom: Left: extracted wavelet; Center: calculated inverse filter; Right: result of convolution of average wavelet with inverse filter, creating a zero-phase wavelet. FFID, field file identification number; ms, millisecond. 


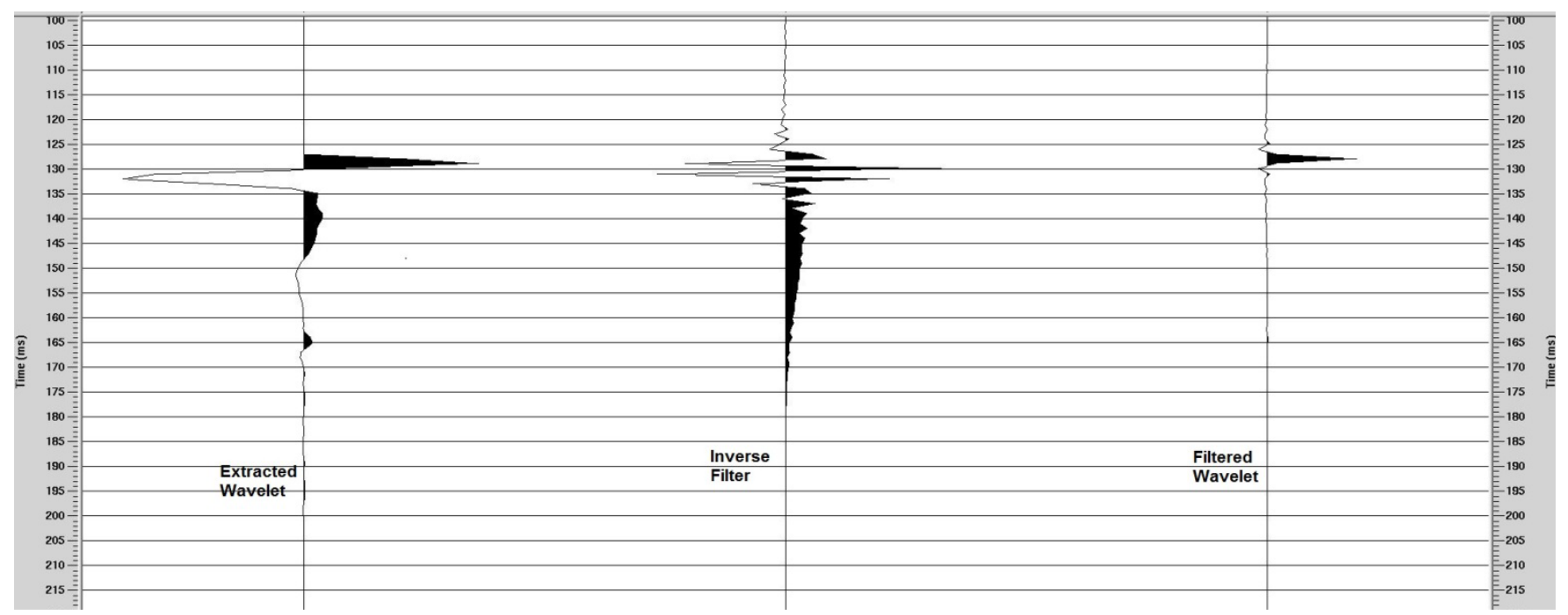

Figure 8. Wavelet extraction, calculation of inverse filter, and conversion to zero-phase wavelet. Top: Average wavelets extracted from the Walker Ridge 200-series lines. The sources were 2x45/45 cubic inches except where noted. For each source, the extracted wavelets are quite similar. Middle: Enlarged version of top displayed at higher gain, showing the consistency in the wavelet tails for the different sources. Bottom: Left: extracted wavelet; Center: calculated inverse filter; Right: result of convolution of average wavelet with inverse filter, creating a zero-phase wavelet. FFID, field file identification number; ms, millisecond.-Continued

Figure 9 (top) shows an unmigrated stack from Walker Ridge with no deconvolution applied. Figure 9 (bottom) has been processed using prestack wavelet deconvolution. The temporal resolution of the reflections has been greatly increased, and the wavelet has been converted to zero phase. It should be noted that the seafloor does not appear as a pure zero-phase wavelet, most likely because there is layering immediately beneath the seafloor, giving rise to constructive and destructive interference. 

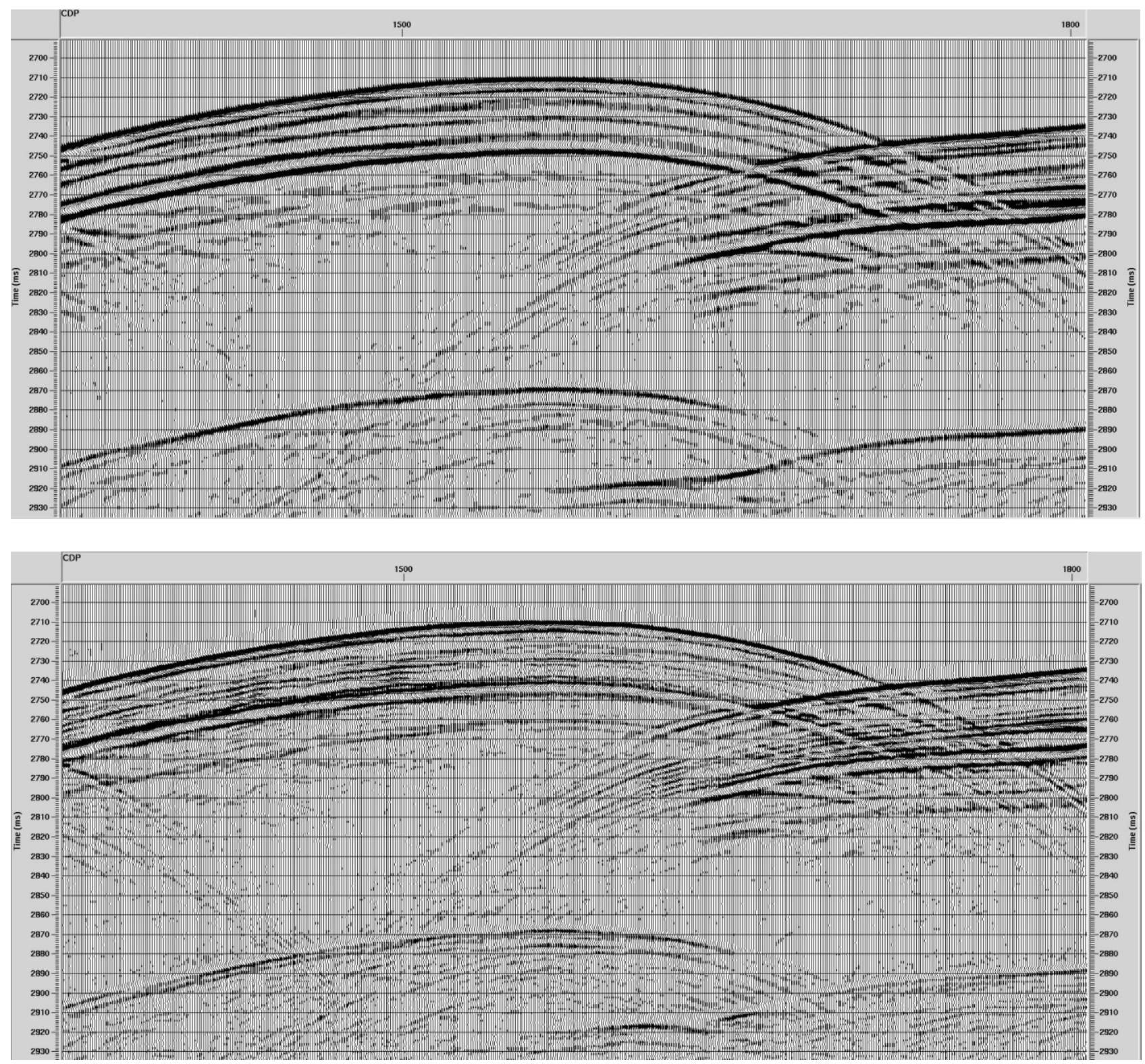

Figure 9. Top: Walker Ridge unmigrated stack with no deconvolution applied. Bottom: Data from top with prestack wavelet deconvolution applied. The minimum-phase wavelet has been collapsed into a zero-phase wavelet and the temporal resolution has been greatly increased. CDP, common depth point; ms, millisecond.

The effect of wavelet deconvolution on the Green Canyon lines is more dramatic (fig. 10) and can be clearly seen at the seafloor reflection because there does not appear to be much layering immediately beneath it. Figure 10 (top) shows an unmigrated stack from Green Canyon with no deconvolution applied; red ovals highlight the complex source waveform. In addition, remnants of noise bursts can be seen, some of which are enclosed in green ovals. Figure 10 (bottom) shows the same data after wavelet deconvolution has been applied. The seafloor reflection appears as a zero-phase wavelet, and as with the Walker Ridge data, the temporal resolution is greatly increased. In addition, the remnants of the noise bursts have been largely eliminated. 

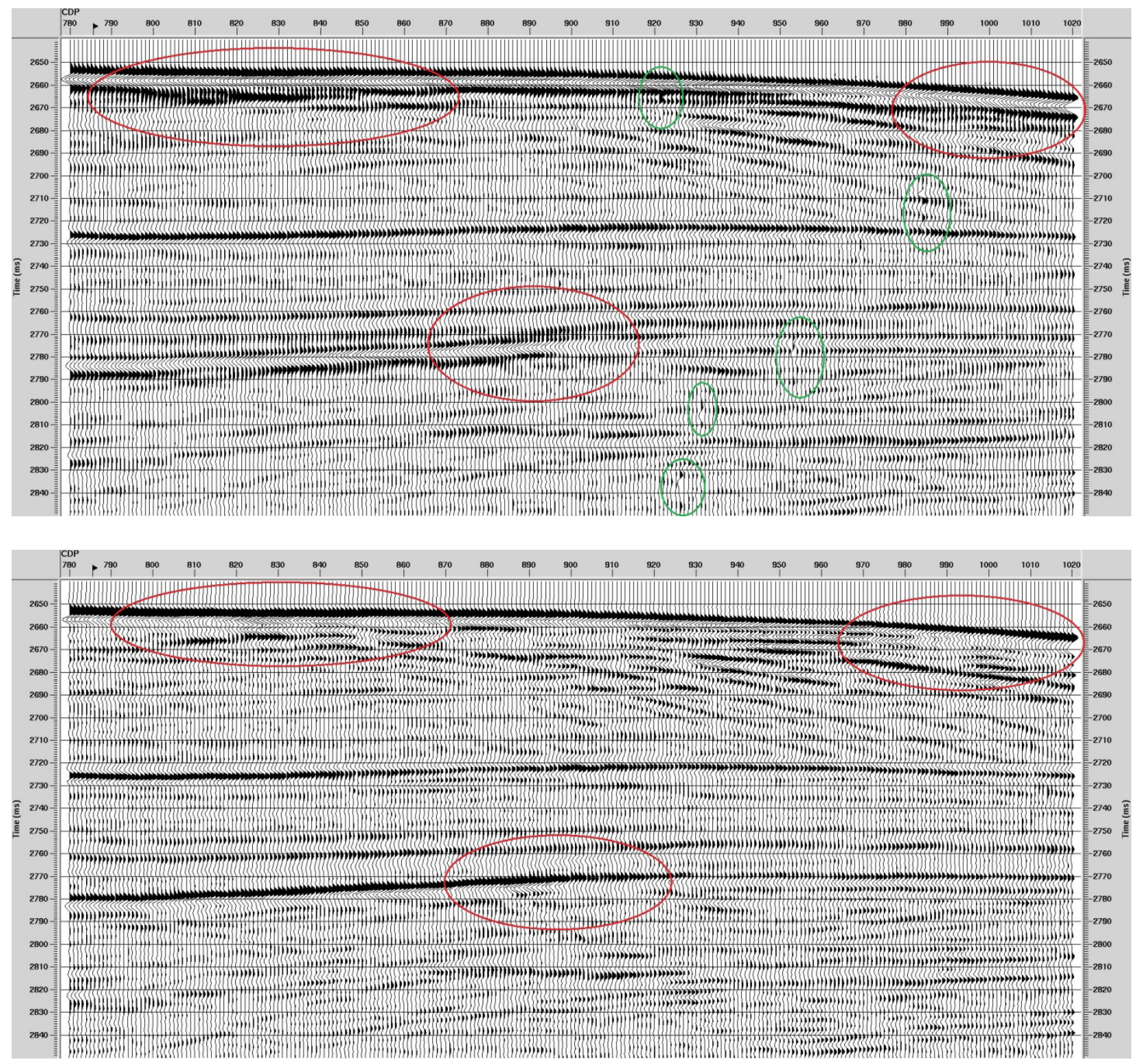

Figure 10. Top: Unmigrated stack from Green Canyon with no deconvolution applied. The complex source waveform can be seen, highlighted in the red ovals and some of the remnants of noise bursts can be seen inside of the green ovals. Bottom: Data from top with wavelet deconvolution applied. The minimum-phase wavelet has been collapsed into a zero-phase wavelet, temporal resolution has been greatly increased and noise has been reduced. CDP, common depth point; $\mathrm{ms}$, millisecond. 


\section{True Relative Amplitude Stacking and Migration}

To create a TRA section for each line, we used the data that had noise elimination and wavelet deconvolution applied and performed the following steps:

Scaling-1: Calculate a single scalar for each shot that would equalize the average amplitude of each shot gather using a time window that began slightly above the seafloor reflection and ended slightly above the seafloor multiple.

Scaling-2: Programmed gain function of two-way travel time raised to the power of 2 ( $\mathrm{T}$ squared gain). Programmed gain curve $-t^{* * 2}$ applied to 5-second maximum TWTT.

Bandpass filter: $35-375 \mathrm{~Hz}$ Butterworth.

NMO and stacking: Velocities were those used for the kinematic processing; 1/SQRT (fold) mute compensation.

Poststack time migration: Velocities were those used for the kinematic processing; Stolt F-K algorithm using the smoothed velocity model.

Initial interpretations and analysis of selected lines from the TRA dataset are given in Haines and others (2014b).

\section{Comparison of the Processing Results}

Figure 11 shows a comparison of the shipboard processing (top) to the basic kinematic processing performed in Denver (bottom). Neither have had deconvolution applied, but the Denver processing used a velocity model determined by detailed velocity analysis for stacking. The linear noise trains can be seen in both sections, some of which are enclosed in red ovals on the shipboard processing. Because the cable length $(450 \mathrm{~m})$ is much shorter than the depths to the seafloor $(2,000 \mathrm{~m}$ at CMP 1500) and target horizons, the velocity resolution was limited, and not much difference in the stacking response can be seen using the detailed velocities. However, these velocity differences are much more important in the migration response. 

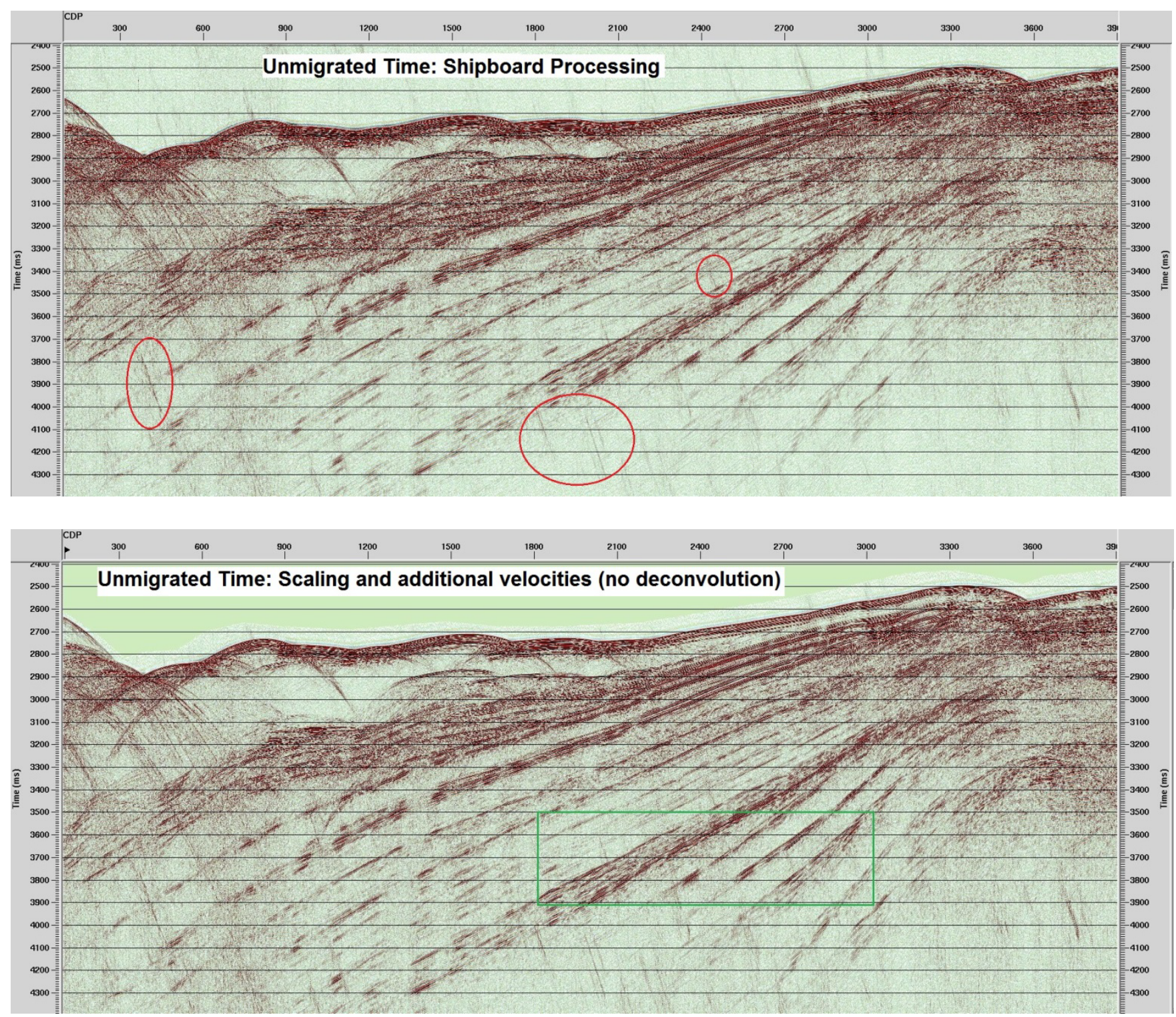

Figure 11. Comparison of shipboard processing with basic processing performed in Denver, Colorado. Top: Shipboard processing using unknown scaling and a single velocity function derived from well data. Linear noise trains are enclosed in red ovals. Bottom: Processing (in Denver) using conventional scaling and additional velocities determined from the data. Although the type of scaling is different, the linear noise trains can be seen on both images (red ovals in top display). Application of additional velocity analysis has improved the continuity of the reflections. Green box indicates area shown in figure 13, top. CDP, common depth point; ms, millisecond.

Figure 12 shows the kinematic processing, TRA processing, and migration of the TRAprocessed data. The kinematic processing (top) has effectively removed the noise, but the amplitude information cannot be interpreted. The TRA processing (middle) preserves the amplitude information and has more accurate deconvolution. The migration of the TRA (bottom) correctly positions the reflections. Although subtle differences may be difficult to see in figure 12, expanded versions are given in figures 13 and 14 (green boxes) and figure 15 (red box). 

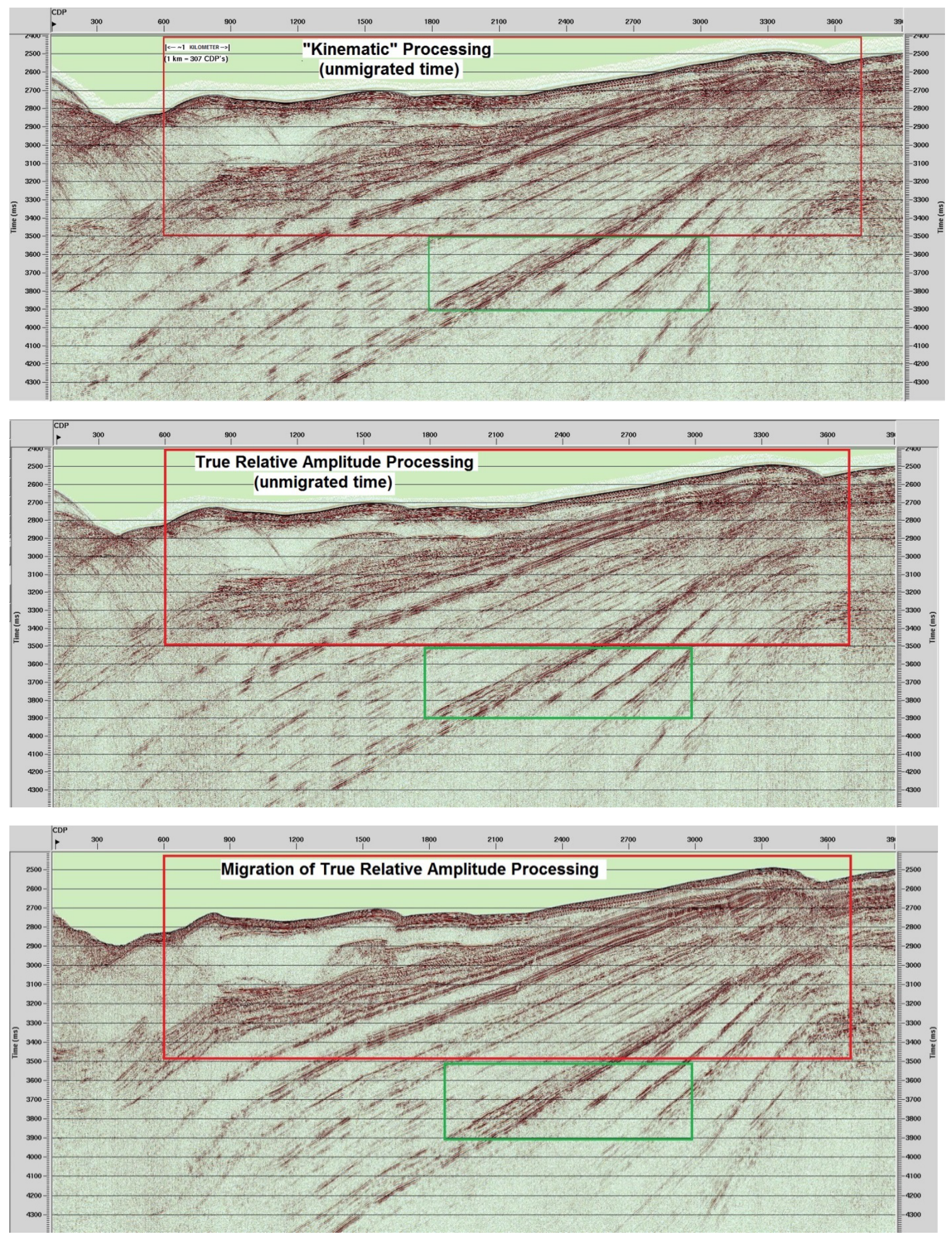

Figure 12. Comparison of kinematic, true relative amplitude (TRA), and migration of TRA processing. Top: Unmigrated stack with "kinematic" processing. Noise has been effectively removed by F-K filtering and noise 
burst removal, but this section cannot be analyzed for relative amplitude information. Middle: Unmigrated stack with wavelet deconvolution and TRA processing. Linear noise has been manually removed and isolated noise bursts have been automatically deleted. This version of the processing can be analyzed for relative amplitude information. Bottom: Post stack time migration of TRA processing using a smoothed version of the stacking velocities. Diffractions have been collapsed and reflections positioned correctly. Green boxes indicate area displayed in figures 13 and 14; Red boxes indicate area displayed in figure 15. CDP, common depth point; $\mathrm{ms}$, millisecond.

The effect of noise removal can be seen by comparing the top and middle images of figure 13 . Linear noise trains are apparent in figure 13 (top) that make TRA scaling impossible. This noise has been removed in figure 13 (middle) resulting in increased confidence in the amplitude information. A reflection from a free-gas zone is indicated by the green arrow. This feature cuts across geologic structure and can be considered part of a bottom-simulating reflector (BSR) commonly seen in areas containing gas hydrates. Figure 13 (bottom) shows the result of the TRA processing after wavelet deconvolution. The temporal resolution of the reflections have been greatly increased, and the onset of the BSR is now negative (black) which is expected at the top of a free-gas zone.

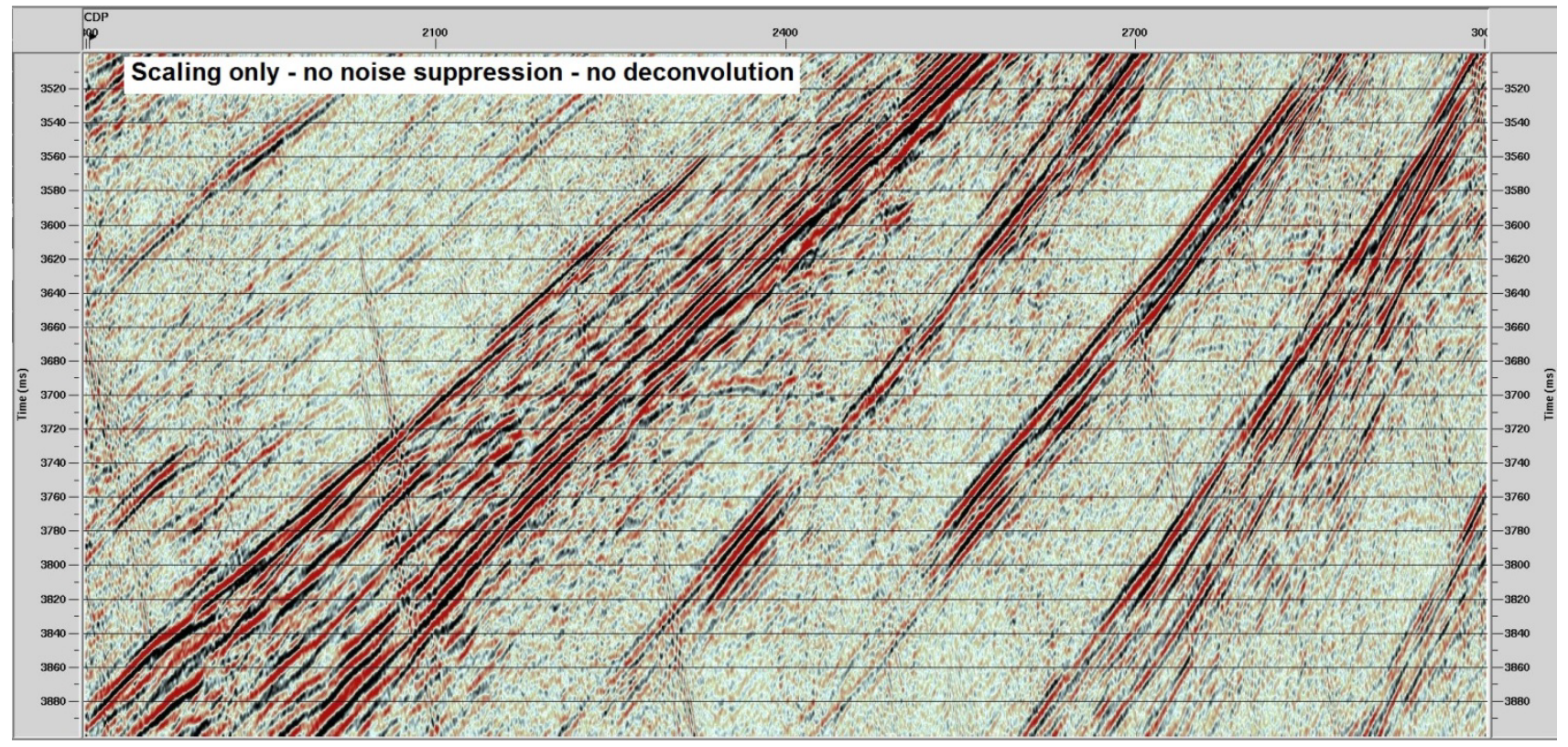

Figure 13. Area within green boxes on figures 11 and 12. Top: Scaling only; no deconvolution. Linear noise trains are clearly contaminating the data, indicating that scalars calculated for true relative amplitude (TRA) processing will be erroneous. Middle: Section processed after manual and automatic removal of noise and TRA scaling. Green arrow indicates a possible free-gas zone. This is also referred to as a bottom-simulating reflector (BSR). Bottom: Noise editing, wavelet deconvolution, and TRA scaling. Wavelet deconvolution has increased the temporal resolution of the reflections and has converted the onset of the possible free-gas reflection to negative polarity (black) which is to be expected. CDP, common depth point; ms, millisecond. 

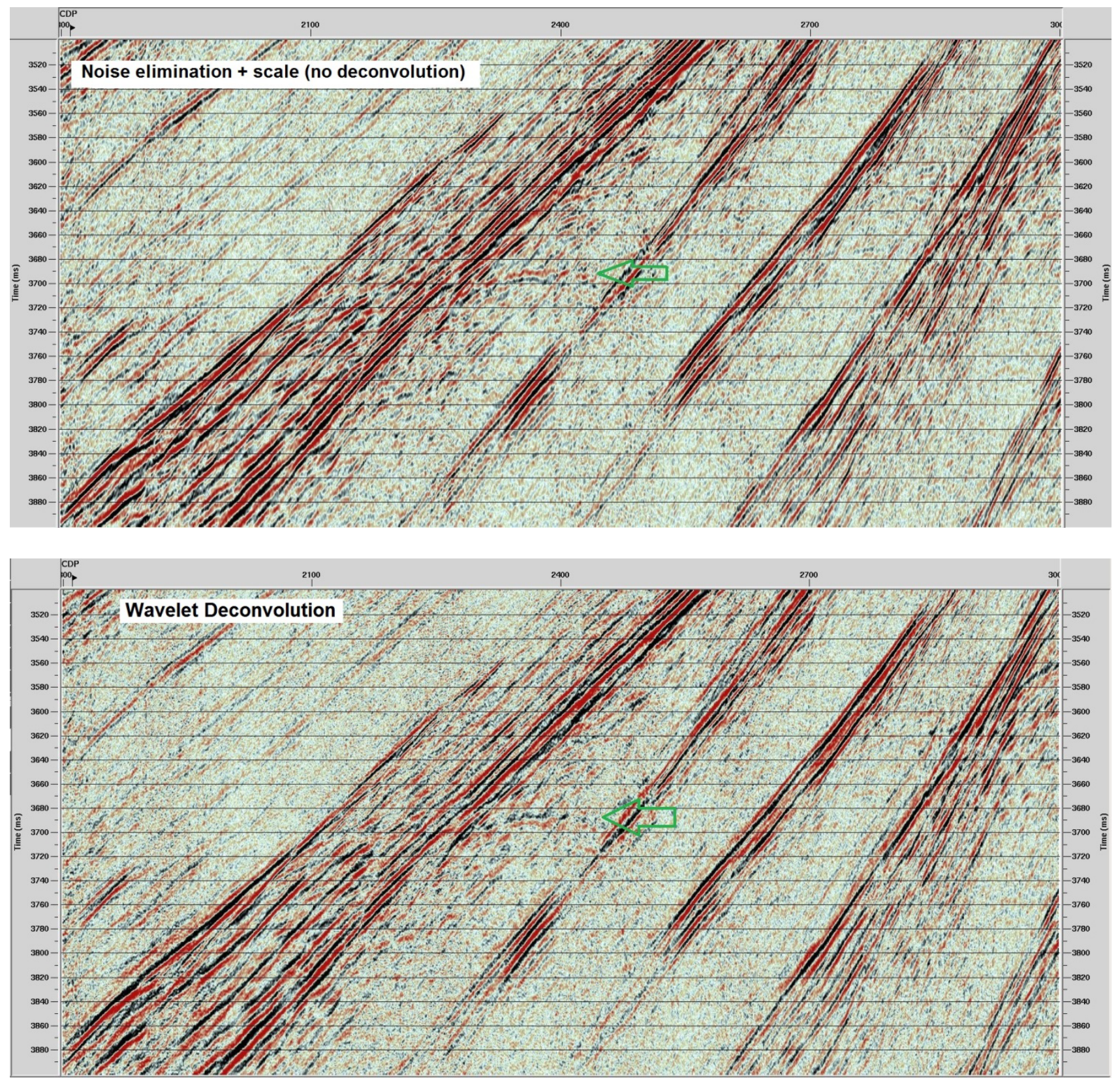

Figure 13. Area within green boxes on figures 11 and 12. Top: Scaling only; no deconvolution. Linear noise trains are clearly contaminating the data, indicating that scalars calculated for true relative amplitude (TRA) processing will be erroneous. Middle: Section processed after manual and automatic removal of noise and TRA scaling. Green arrow indicates a possible free-gas zone. This is also referred to as a bottomsimulating reflector (BSR). Bottom: Noise editing, wavelet deconvolution, and TRA scaling. Wavelet deconvolution has increased the temporal resolution of the reflections and has converted the onset of the possible free-gas reflection to negative polarity (black) which is to be expected. CDP, common depth point; $\mathrm{ms}$, millisecond.-Continued

Figure 14, top, again shows the TRA processing after wavelet deconvolution, unmigrated (same section as that shown in figure 13, bottom) while figure 14, bottom, shows the migrated version. The 
migration has positioned the reflections correctly, has collapsed the BSR into a higher amplitude event, and shows event truncations and polarity reversals (shown in the red oval, some of which are indicated by green lines), which indicate the base of the gas hydrate stability zone (BHSZ), above which may be gas hydrate deposits and below which may be free gas.
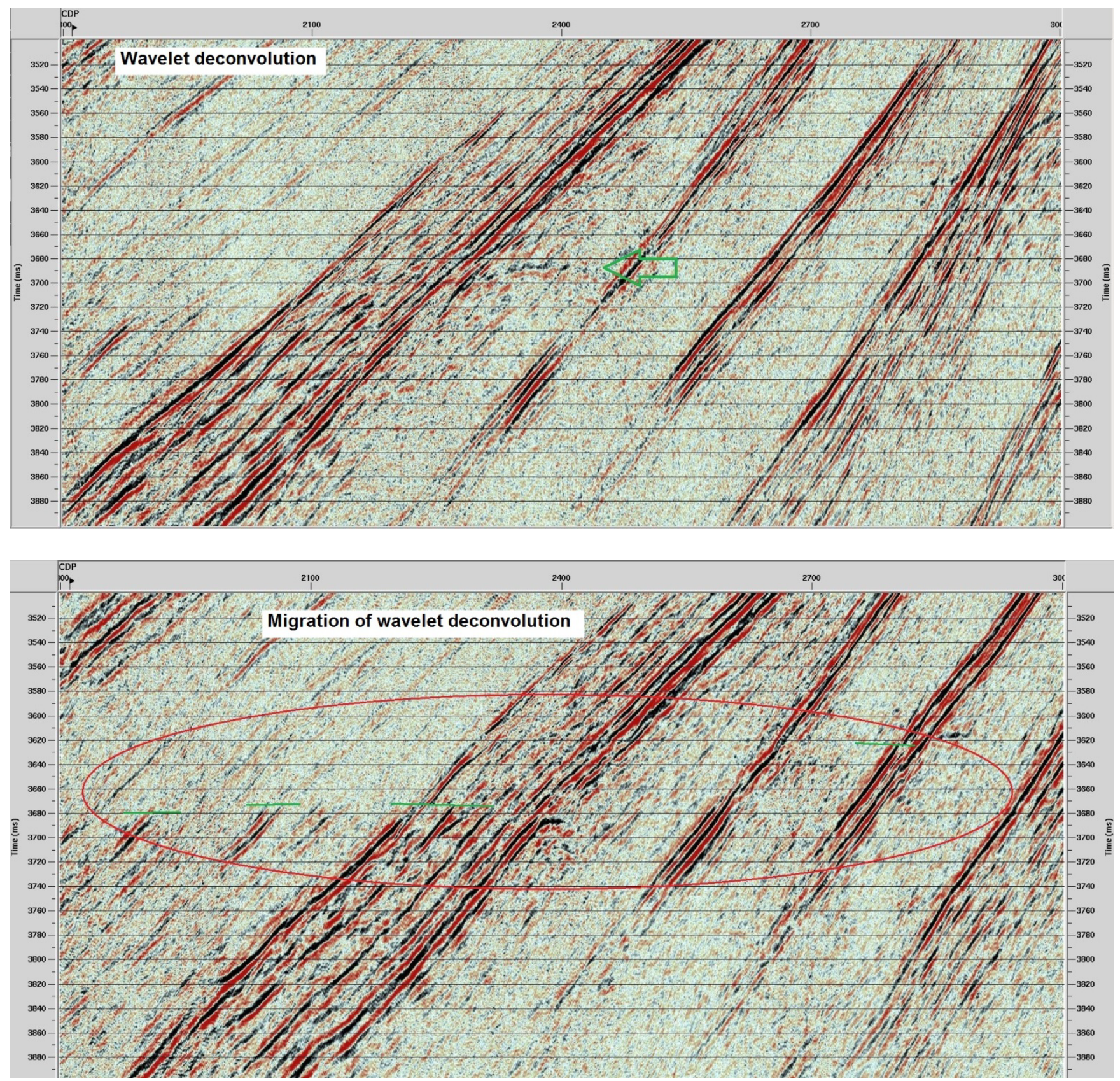

Figure 14. Area contained within green boxes on figure 12. Top: Unmigrated stack with wavelet deconvolution and true relative amplitude processing. Arrow indicates reflection from a possible free-gas zone. This is the same as figure 13, bottom. Bottom: Migrated data from top. Free-gas zone has been collapsed and is higher amplitude. Reflections have been properly positioned updip. Red circle encloses truncations and polarity 
reversals, some of which are indicated by green lines, indicating the base of the gas hydrate stability zone (BHSZ) where gas hydrate deposits lie above and free gas below. CDP, common depth point; ms, millisecond.

Figure 15 shows the effect of migration (bottom) performed on the TRA processing (top). This is the area enclosed in the red boxes on figure 12. The migration clearly reveals detailed faulting and folding and indicates that the velocity model used to migrate the data is correct.
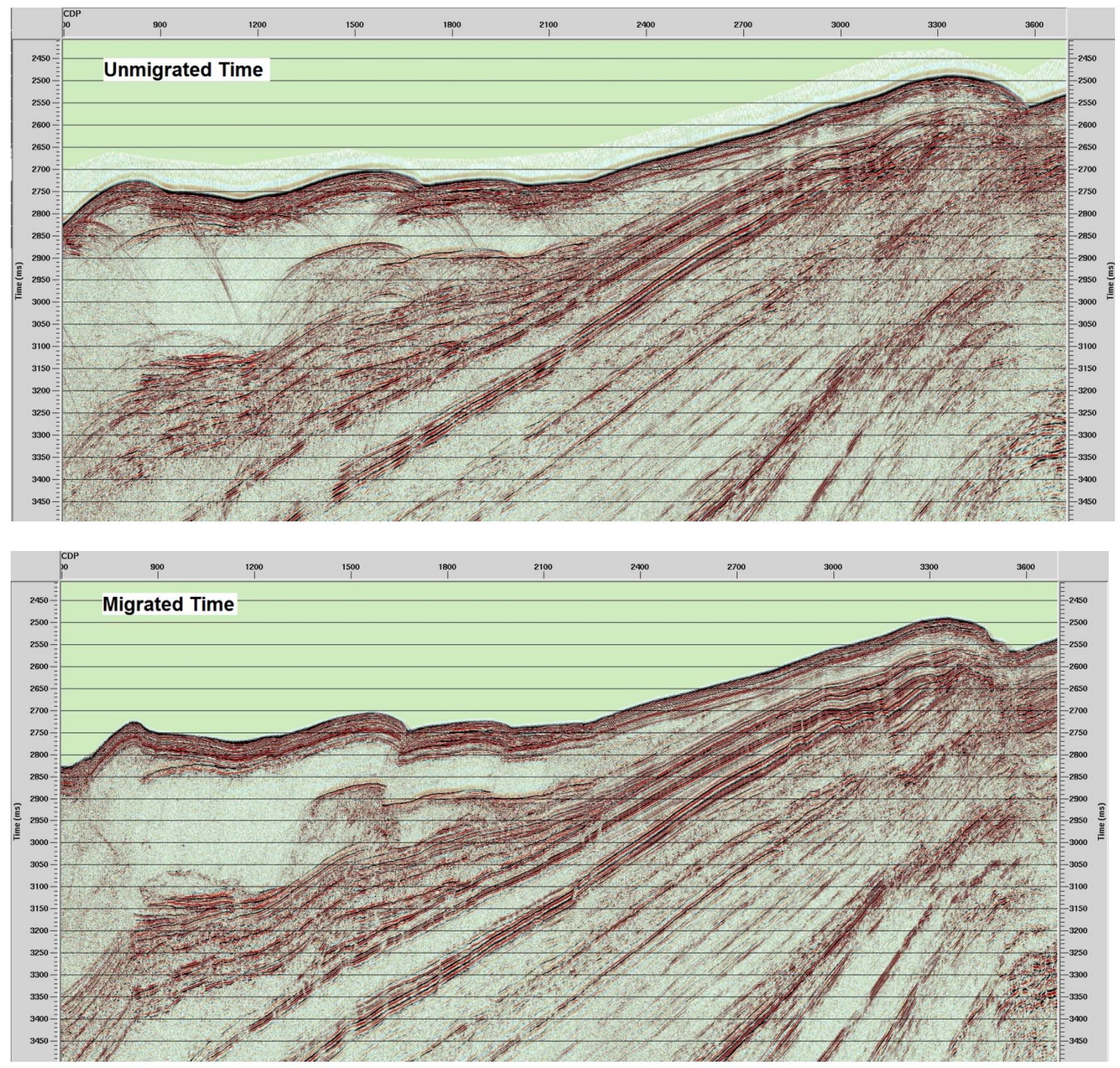

Figure 15. Area contained within red boxes on figure 12. Top: Unmigrated true relative amplitude (TRA)processed section (red box on figure 12, middle). Bottom: Migration of data from top (red box on figure 12, bottom). Details of faulting and folding are clear. CDP, common depth point; ms, millisecond. 


\section{Publicly Available, Digital, True Relative Amplitude Data}

All of the processed lines from GC955 and WR313 are available to the public in digital form as standard SEG-Y format files (Barry and others, 1975) located on the National Archive for Marine Seismic Surveys (Triezenberg and others, 2016) Web site at the following URLs: https://walrus.wr.usgs.gov/namss/survey/p1-13-la-green-canyon/ and https:/walrus.wr.usgs.gov/namss/survey/p1-13-la-walker-ridge/. Specialized software is required to view these data. In addition, text files containing navigation information necessary for loading the data onto a seismic interpretation workstation are provided. Appendix 1 gives the method used to create the navigation files. Appendix 2 gives detailed information on how to access the files.

\section{References Cited}

Barry, K.M., Cavers, D.A. and Kneale, C.W., 1975, Report on recommended standards for digital tape formats: Geophysics, 40, no. 2, p. 344-352, accessed January 26, 2016, at http://www.seg.org/resources/publications/misc/technical-standards.

Boswell, Ray, Collett, T., Frye, M., McConnell, D., Shedd, W., Dufrene, R., Godfriaux, P., Mrozewski, S., Guerin, G., and Cook, A., 2009, Gulf of Mexico Gas Hydrate Joint Industry Project Leg IITechnical Summary: Morgantown, W.Va., U.S. Department of Energy National Energy Technology Laboratory, 26 p., accessed May 5, 2014, at http://www.netl.doe.gov/File\%20Library/Research/OilGas/methane\%20hydrates/TechSum.pdf.

Boswell, Ray, Collett, T.S., Frye, M., Shedd, W., McConnell, D.R., and Shelander, D., 2012, Subsurface gas hydrates in the northern Gulf of Mexico: Marine and Petroleum Geology, v. 34, p. 4-30.

Claerbout, J.F., 1985, Imaging the Earth's Interior: Cambridge, Mass., Blackwell Scientific Publications, $398 \mathrm{p}$.

Collett, T.S., Lee, M.W., Zyrianova, M.V., Mrozewski, S.A., Guerin, G., Cook, A.E., and Goldberg, D.S., 2012, Gulf of Mexico Gas Hydrate Joint Industry Project Leg II logging-while-drilling data acquisition and analysis: Marine and Petroleum Geology, v. 34, p. 41-61.

Cook, Ann, Guerin, G., Mrozewski, S., Collett, T.S., and Boswell, Ray, 2009, Gulf of Mexico Gas Hydrate Joint Industry Project Leg II-Walker Ridge 313 LWD operations and results: Morgantown, West Virginia, U.S. Department of Energy National Energy Technology Laboratory, 24 p., accessed May 5, 2014, at http://www.netl.doe.gov/File\%20Library/Research/OilGas/methane\%20hydrates/WR313LWDOps.pdf.

Deregowski, S.M., 1990, Common offset migrations and velocity analysis: First Break, v. 8, no. 6, p. 225-233.

Haines, S.S., Hart, P.E., Shedd, W.W., Frye, M., Agena, W., Miller, J.J. and Ruppel, C.D., 2013, Seismic investigation of gas hydrates in the Gulf of Mexico: Results from 2013 high-resolution 2D and multicomponent seismic surveys, American Geophysical Union, Fall Meeting 2013, abstract \#OS21A-1618.

Haines, S.S., Hart, P.E., Ruppel, C.D., O’Brien, T., Baldwin, W., White, J., Moore, E., Dal Ferro, P., and Lemmond, P., 2014a, Cruise report for P1-13-LA, U.S. Geological Survey gas hydrates research cruise, R/V Pelican April 18 to May 3, 2013, deepwater Gulf of Mexico: U.S. Geological Survey Open-File Report 2014-1080, 33 p., accessed January 26, 2016, at http://dx.doi.org/10.3133/ofr20141080. 
Haines, S.S., Hart, P., Shedd, W.W., and Frye, M., 2014b, 2013 Multicomponent and high-resolution 2D seismic acquisition over known gas hydrate accumulations in the Gulf of Mexico, in International Conference on Gas Hydrates (ICGH8-2014), 8th, Beijing, China, 28 July-1 August, 2014,, Proceedings: China Geological Survey and Chinese Academy of Sciences.

Lee, M.W., 2005, Well Log Analysis to Assist the Interpretation of 3-D Seismic Data at Milne Point, North Slope of Alaska: U.S. Geological Survey Scientific Investigations Report 2005-5048, 18 p., accessed February 26, 2016, at http://pubs.usgs.gov/sir/2005/5048/.

Miller, J.J., Lee, M.W., and von Huene, R., 1991, An analysis of a seismic reflection from the base of a gas hydrate zone, offshore Peru: American Association of Petroleum Geologists Bulletin, v. 75, no. 5, p. 910-924.

Oppenheim, A.V., and Shafer, R.W., 1975, Digital signal processing: Prentice-Hall, Inc., 585 p. Stolt, R.H., 1978, Migration by Fourier transform: Geophysics, v. 43, no. 1, p. $23-48$.

Triezenberg, P.J., Hart, P.E., and Childs, J.R., 2016, National Archive of Marine Seismic Surveys (NAMSS) - A USGS data website of marine seismic reflection data within the U.S. Exclusive Economic Zone (EEZ): U.S. Geological Survey Data Release, accessed February 26, 2016, at http://dx.doi.org/10.5066/F7930R7P.

Yilmaz, Özdoğan, 1987, Seismic data processing: Tulsa, Oklahoma, Society of Exploration Geophysicists, 536 p. 


\section{Appendix 1. Processing Applied to Navigation Data}

The 2013 seismic data acquisition was conducted partially during periods of strong winds and high seas, and the impact on the seismic data quality has been described earlier in this document. In addition, this sea state resulted in some complexities with the navigation data and the resulting calculated common mid-point (CMP) locations. In this section, we describe the approach used to obtain more accurate and (or) useful CMP location estimates. The results of our calculations are stored in separate text files (one for each survey) and should be used to load the data into seismic interpretation software. These text files reside with the processed data on a publicly available Web site described in appendix 2 .

As described by Haines and others (2014), position information was acquired via a global positioning system (GPS) antenna located midship at a height of $15 \mathrm{~m}$ above the main deck and $18 \mathrm{~m}$ from the stern. During periods of high seas and substantial ship roll, the GPS antenna was subject to considerable lateral movement (forward/aft as well as port/starboard). The algorithm used for calculating the CMP locations first determined the shot and receiver positions for each sequential shot and used the apparent heading of the ship (based on the GPS "fixes" for two sequential shots) to establish the position of the streamer and source based on the assumption that the streamer extended behind the ship (opposite to the heading direction). Thus, when the sea state caused the GPS position of two or more sequential shots to indicate ship motion in a direction opposite to the actual heading, the algorithm calculated positions based on the streamer being ahead of the ship. This occurred for a few shots on a few of the seismic lines that were recorded in particularly high seas, and when present, the phenomenon caused considerable problems with the calculated CMP positions. In addition, some similar impacts may have occurred on some lines simply due to GPS error.

A second, lesser problem occurred when the sea state was rough but not so rough as to cause the heading of the ship to appear opposite to the true heading. In these situations, the CMP positions may have been calculated approximately correctly, but the resulting apparent seismic transect was so far from linear as to complicate interpretation. This problem impacted most of the lines at Green Canyon 955 (GC955) and some lines at Walker Ridge 313 (WR313).

We approached these related, but distinct, problems with a two-part strategy. First, for those lines that showed problems associated with apparent backward ship motion and, thus, severely problematic calculated CMP positions, we simply removed the position information for the offending sections of the navigation data and replaced it with linearly interpolated positions. We conducted this operation for 10 lines at GC955 $(111 \mathrm{~B}, 145,147,151,153,155,155 \mathrm{~A}, 157,159,161)$ and 5 lines at WR313 (143, 229C, 233, 321N, 341). For the lines at GC955 where seismic transect orientations were primarily north-south and east-west, we performed this operation only on the coordinate that was in-line with the transect orientation, leaving the transverse coordinate as originally recorded. For the lines at WR313, we performed the deletion and interpolation for both coordinates.

Second, for all seismic lines, we performed a simple smoothing operation to address the secondary problem. We accomplished this by performing what is essentially a one-dimensional lowpass filtering separately on the northing and easting coordinates. The filter parameter was chosen to minimize excessive trackline "jumpiness" without impacting the general line position.

Figure 1-1 shows an example of the two-step navigation processing for line GC151, one of those that was most impacted by the positional errors. Figure 1-2 shows an example of applying only the smoothing operation to a line with only minimal navigational problems. 

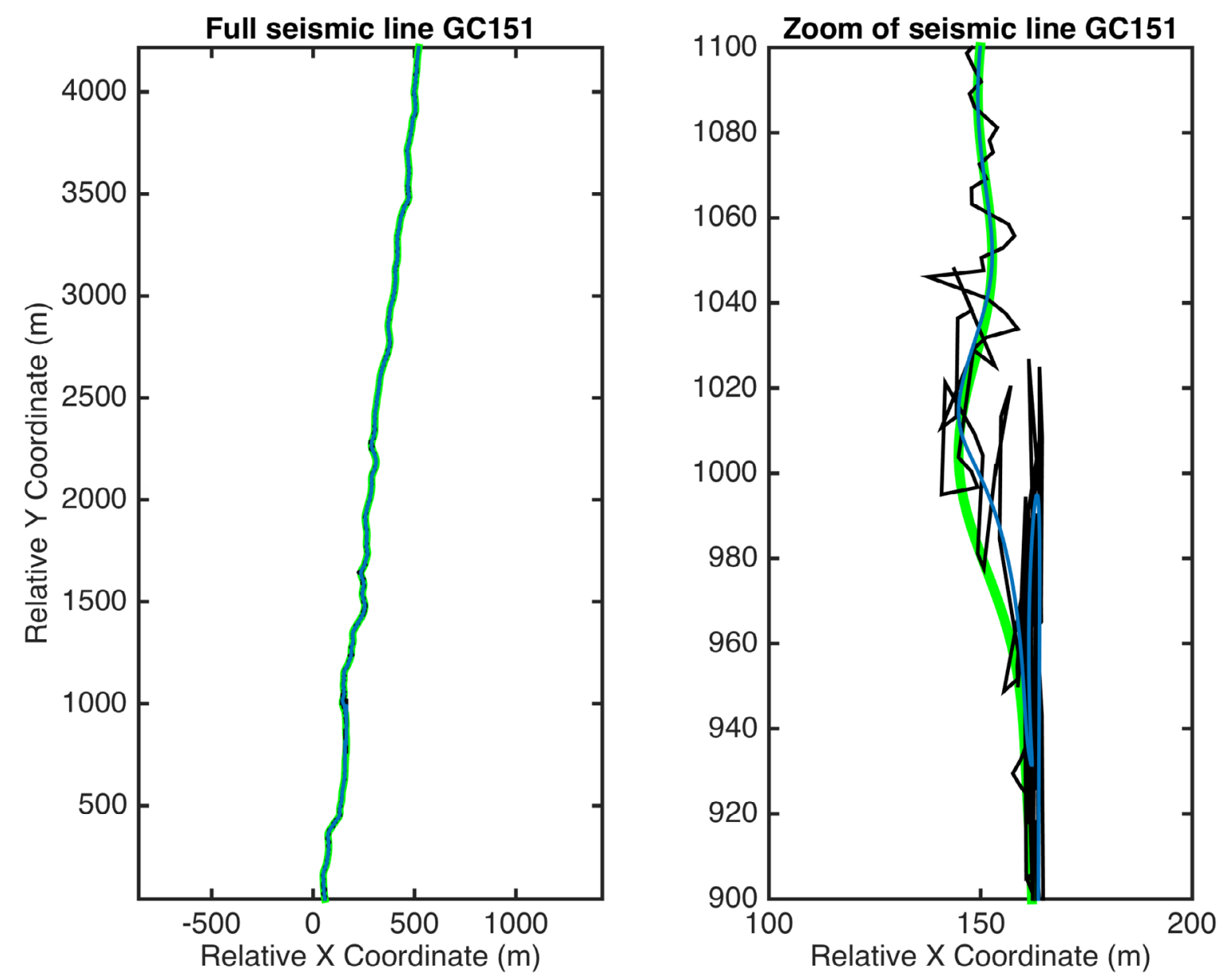

Figure 1-1. Maps of common mid-point positions for line Green Canyon 151 (GC151) with the originally calculated transect plotted as a thin black line and the final transect plotted as a green line. The blue line shows the transect resulting from application of only the smoothing operation to the original data. The panel on the left shows the full transect, and the panel on the right shows a detailed view of one particularly problematic part of the line. Indicated coordinates are relative to an arbitrarily chosen point to simplify the display. $m$, meters. 

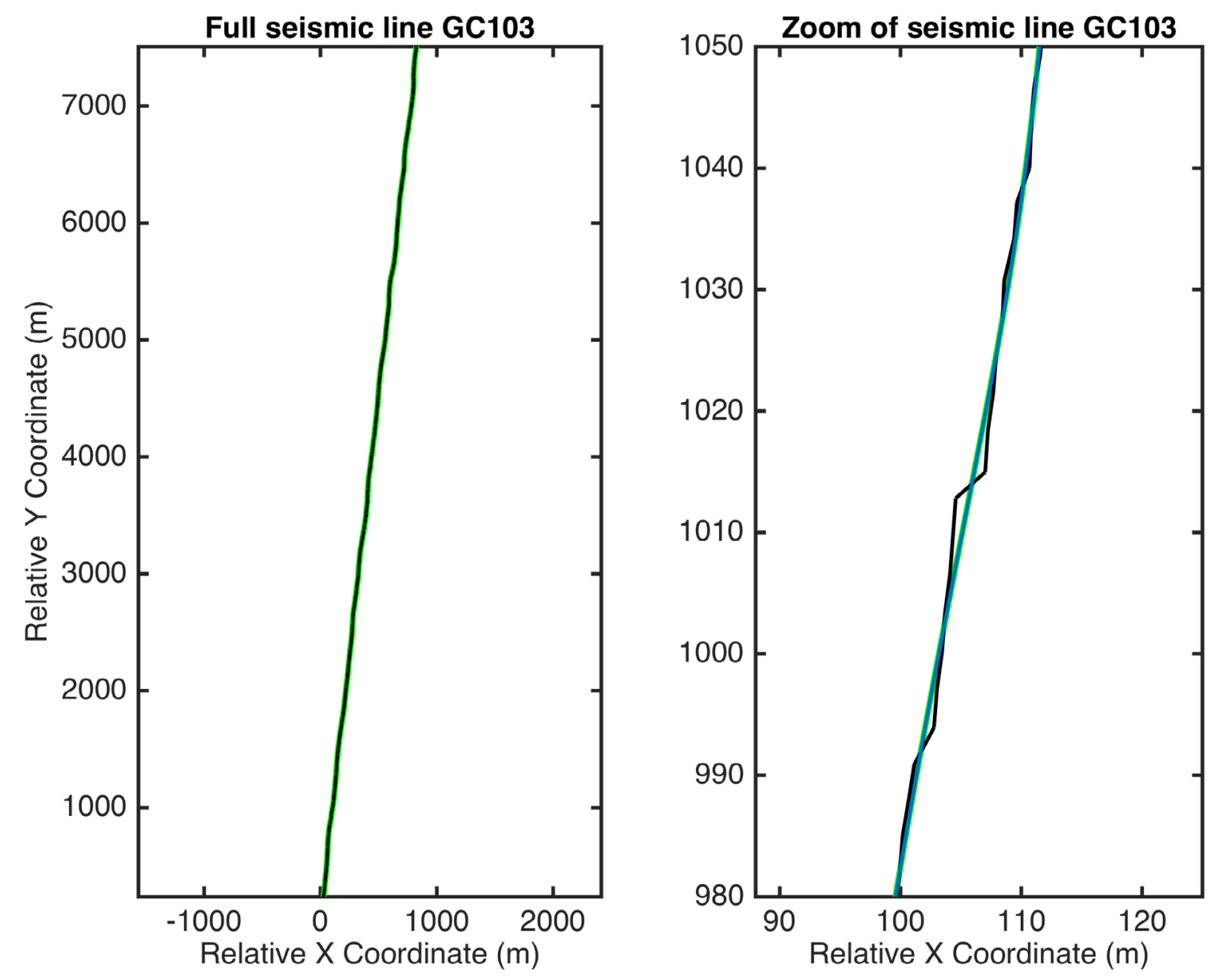

Figure 1-2. Maps of common mid-point positions for line Green Canyon 103 (GC103) with the originally calculated transect plotted as a thin black line and the final transect plotted as a green line. The panel on the left shows the full transect, and the panel on the right shows a detailed view of one particularly problematic part of the line. Indicated coordinates are relative to an arbitrarily chosen point to simplify the display.

\section{Reference Cited}

Haines, S.S., Hart, P.E., Ruppel, C.D., O'Brien, T., Baldwin, W., White, J., Moore, E., Dal Ferro, P., and Lemmond, P., 2014, Cruise report for P1-13-LA, U.S. Geological Survey gas hydrates research cruise, $R / V$ Pelican April 18 to May 3, 2013, deepwater Gulf of Mexico: U.S. Geological Survey Open-File Report 2014-1080, 33 p., accessed January 26, 2016, at http://dx.doi.org/10.3133/ofr20141080. 


\section{Appendix 2. Instructions on How to Access the Publicly Available Digitally Processed Data}

All of the processed lines from Green Canyon 955 (GC955) and Walker Ridge 313 (WR313) are available to the public in digital form as standard Society of Exploration Geophysicists Y format files (SEG-Y; Barry and others, 1975) located on the National Archive for Marine Seismic Surveys (Triezenberg and others, 2016) Web site at the following URLs: https://walrus.wr.usgs.gov/namss/survey/p1-13-la-green-canyon/ and https://walrus.wr.usgs.gov/namss/survey/p1-13-la-walker-ridge/.

The sites include general survey information, links to download seismic metadata, zip files containing SEG-Y and navigation files, and the cruise report (Haines and others, 2014). The data are the final processed results in migrated and unmigrated forms. Each SEG-Y file contains generalized acquisition and processing information in its EBCDIC header (given below). The navigation data have been processed as described in appendix 1, and the positions in the navigation files should be used to load the data into seismic interpretation software.

EBCDIC header contained in all of the SEG-Y files:

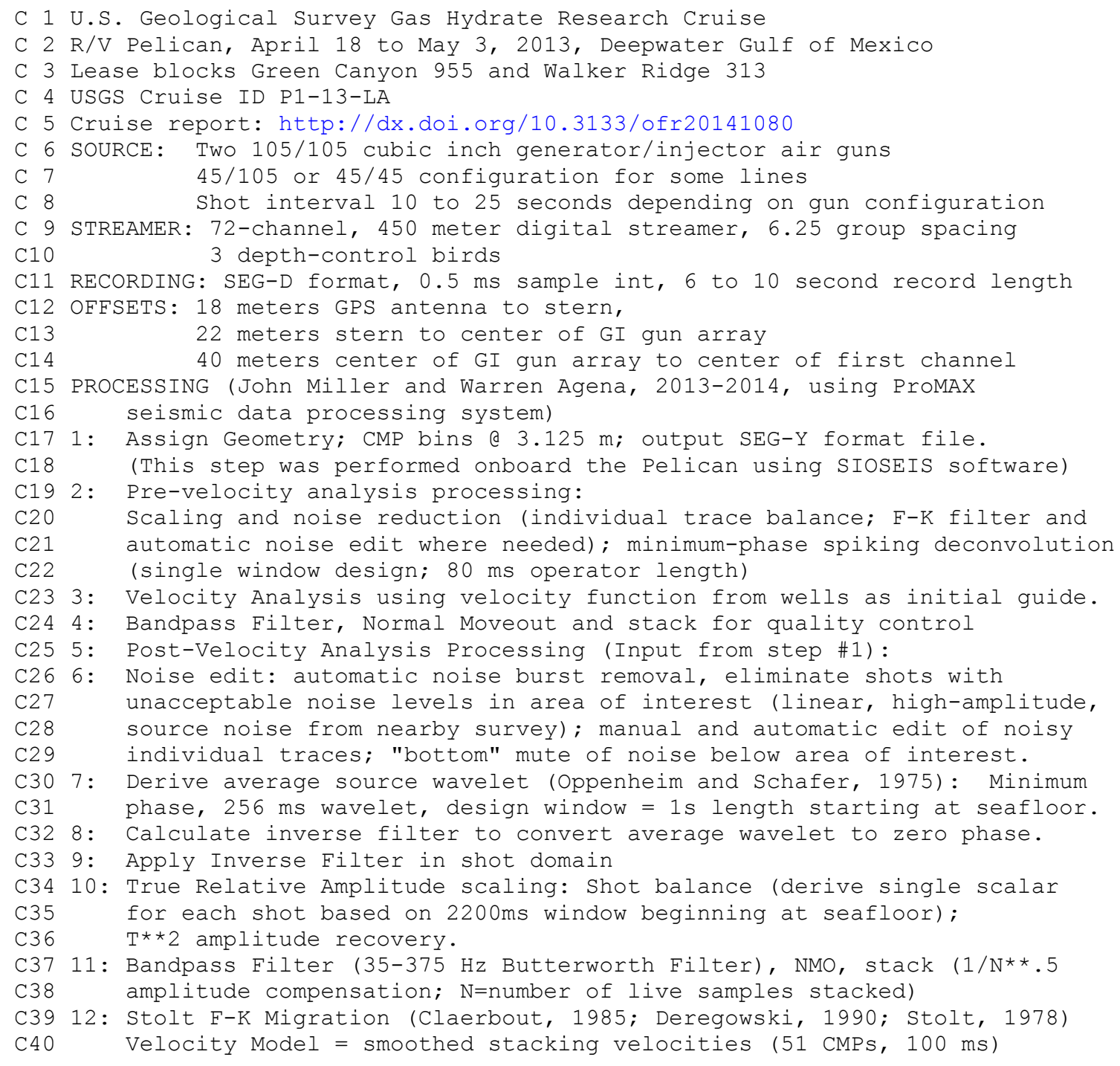




\section{References Cited}

Barry, K.M., Cavers, D.A. and Kneale, C.W., 1975, Report on recommended standards for digital tape formats: GEOPHYSICS, 40, no. 02, p. 344-352, accessed January 26, 2016, at http://www.seg.org/resources/publications/misc/technical-standards.

Claerbout, J.F., 1985, Imaging the Earth's Interior: Cambridge, Mass., Blackwell Scientific Publications, 398 p.

Deregowski, S.M., 1990, Common offset migrations and velocity analysis: First Break, v. 8, no. 6, p. 225-233.

Haines, S.S., Hart, P.E., Ruppel, C.D., O’Brien, T., Baldwin, W., White, J., Moore, E., Dal Ferro, P., and Lemmond, P., 2014, Cruise report for P1-13-LA, U.S. Geological Survey gas hydrates research cruise, $R / V$ Pelican April 18 to May 3, 2013, deepwater Gulf of Mexico: U.S. Geological Survey Open-File Report 2014-1080, 33 p., accessed January 26, 2016, at http://dx.doi.org/10.3133/ofr20141080.

Oppenheim, A.V., and Shafer, R.W., 1975, Digital signal processing: Prentice-Hall, Inc., 585 p. Stolt, R.H., 1978, Migration by Fourier transform: Geophysics, v. 43, no. 1, p. 23-48.

Triezenberg, P.J., Hart, P.E., and Childs, J.R., 2016, National Archive of Marine Seismic Surveys (NAMSS): A USGS data Web site of marine seismic reflection data within the U.S. Exclusive Economic Zone (EEZ): U.S. Geological Survey Data Release, accessed February 26, 2016, at http://dx.doi.org/10.5066/F7930R7P. 